\title{
EL INDIVIDUO COMO SUJETO DE DERECHO INTERNACIONAL. ANÁLISIS DE LA DIMENSIÓN ACTIVA DE LA SUBJETIVIDAD JURÍDICA INTERNACIONAL DEL INDIVIDUO
}

\author{
Juan Pablo PÉREZ-LEÓN*
}

RESUMEN: Una de las características del derecho internacional público contemporáneo es el afianzamiento de la subjetividad jurídica del individuo. Precisamente, el presente artículo plantea analizar la dimensión activa de tal subjetividad, es decir, la titularidad efectiva de derechos ante tribunales internacionales. Para este propósito, en primer lugar, se hará referencia a la evolución de la subjetividad individual, así como a ciertas teorías sobre este tema. A continuación, se atenderá la participación del individuo en los sistemas internacionales de protección de derechos humanos tanto universal como regionales. Finalmente, se estudiará la situación de las víctimas ante la Corte Penal Internacional.

ABSTRACT: Contemporary international public law has as one of its characteristics the consolidation of legal individual subjectivity. Precisely, this paper seeks to analyze the active dimension of such subjectivity, it means, the effective right to individual claims before international tribunals. In order to reach the above-mentioned purpose, firstly, a reference to the evolution of individual subjectivity will be done as well as theories about this topic. Then, we will focus on the individual's participation in the international systems of human rights protection regarding the universal system and regional approaches, too. Finally the victim's situation before the International Criminal Court will be studied.

RÉSUMÉ: Une caractéristique du Droit international public contemporain est la consolidation de la subjectivité juridique de l'individu. Précisément, cet article a le but d'analyser la dimension active de la déjà mentionné subjectivité, c'est-à-dire, l'exercice effective de droits devant les tribunaux internationaux. Pour ce propos, nous ferons référence, premièrement, à la subjectivité de l'individu ainsi qu'aux théories sur cet affaire. Après, l'attention sera sur la participation de l'individu dans les systèmes internationaux de protection de droits de l'homme tant universelle comme régionales. Finalement, on étudiera la situation des victimes devant la Cour Pénale Internationale.

* Profesor de Derecho penal internacional en la Pontificia Universidad Católica de Perú. 
SUMARIO: I. La subjetividad jurídica internacional del individuo. II. Dimensión activa. Titularidad efectiva de derechos. III. A manera de conclusión.

\section{LA SUBJETIVIDAD JURÍDICA INTERNACIONAL DEL INDIVIDUO}

\section{Situación del individuo en el derecho internacional clásico}

El derecho internacional clásico se basó en un escenario constituido por una comunidad internacional ${ }^{1}$ en la que predominaba una estructura interestatal. En tal sentido, el derecho internacional clásico poseía una finalidad principalmente de tipo relacional y competencial; es decir la regulación de las relaciones entre Estados y la distribución de las competencias entre ellos. ${ }^{2}$ Esta postura originó que los Estados fueran considerados como los únicos sujetos de derecho internacional, y desde una perspectiva doctrinal los individuos eran sólo objeto del derecho internacional.

Se consideraba como sujetos de derecho internacional sólo a las entidades que creaban y eran destinatarias de las normas jurídicas internacionales y que poseían legitimidad para reclamar (si había incumplimiento de tales normas) o eran responsables (si las infringían). De ese modo, tradicionalmente el sistema jurídico internacional no hacía referencia al individuo sino por medio del Estado, lo cual estaba condicionado por la noción misma de Estado y por la posición de las relaciones interestatales, ${ }^{3}$ siendo un ejemplo de esta situación la figura de la protección diplomática. ${ }^{4}$

1 Se distinguen cuatro grandes etapas en la evolución de la comunidad internacional: 1) Desde la paz de Westphalia hasta el fin de la Primera Guerra Mundial; 2) Desde el fin de la Primera Guerra Mundial hasta el fin de la Segunda Guerra Mundial; 3) Desde la Carta de la Organización de Naciones Unidas hasta el fin de la guerra fría y 4) Desde el fin de la guerra fría hasta el presente. Para mayores detalles, cfr. Cassese, Antonio, International Law, 2a. ed., Oxford-Nueva York, Oxford University Press, 2005, pp. 22 y ss.

2 En opinión de Pastor Ridruejo, el derecho internacional clásico (hasta 1945) se caracterizó por ser liberal, descentralizado y oligárquico. Pastor Ridruejo, José Antonio, Curso de Derecho Internacional Público, 9a. ed., Madrid, Tecnos, 2003, p. 60.

3 Eventualmente, los individuos participaban en los asuntos internacionales ya sea como "beneficiarios" de tratados de comercio y navegación o de convenciones respecto al trato de extranjeros, o como "puntos de referencia" de los poderes estatales, lo cual es ejemplificado por la costumbre estatal de brindar protección diplomática o incluso protección judicial a sus nacionales afectados por un Estado extranjero.

4 Recordemos que en la figura de la protección diplomática, el Estado hace suya la reclamación del particular perjudicado por la violación de una obligación internacional 
Una primera aproximación nos ofrece la noción de población como elemento constitutivo del Estado, noción que no hace referencia al individuo sino al Estado. En este marco, los individuos que no poseen la condición de residentes son calificados como extranjeros, no siendo parte de la población del Estado. ${ }^{5}$ Desde este punto de vista, "l'individu n'intéresse le droit international qu'en tant que ressortissant ou étranger, et dans la mesure où cette qualité concerne les rapports interétatiques". ${ }^{6}$

En igual sentido, se dirigían las doctrinas dualistas, en lo referente a las relaciones entre el derecho internacional y los derechos internos estatales. La estricta separación entre el derecho internacional y los derechos de los Estados aislaban al individuo del derecho internacional. Únicamente si "éste se convertía en derecho interno podía ser invocado por el individuo o, en sentido más amplio, por los particulares, personas físicas o jurídicas". ${ }^{7}$

Entre las teorías negadoras de la subjetividad jurídica internacional del individuo en el derecho internacional clásico, tenemos al positivismo clásico. ${ }^{8}$ Esta teoría se basaba en considerar al Estado como único sujeto de derecho internacional, en tanto esta disciplina jurídica era resultado de la voluntad estatal y el individuo era solamente sujeto de derecho inter-

cometida por otro Estado. Por lo tanto, esta institución jurídica es una manifestación de la subjetividad jurídica internacional del Estado, mas no del individuo. Cfr. Pastor Ridruejo, José Antonio, op. cit., nota 2, pp. 236 y ss.

5 En tal sentido, la población es entendida como el conjunto de individuos vinculados de manera estable al Estado por un vínculo jurídico, el vínculo de nacionalidad. La población es, por lo tanto, el conjunto de nacionales. Asimismo, la nacionalidad crea "une allégeance personnelle de l'individu envers l'État national; elle fonde la compétence personnelle de l'État, compétence qui l'autorise à exercer certains pouvoirs sur ses nationaux où qu'ils se trouvent". Quoc, Nguyen, Daillier, Patrick y Pellet, Alain, Droit International Public, París, Librairie Générale de Droit et de Jurisprudence, 2002, p. 409.

6 Abellán, Victoria, "La responsabilité internationale de l'individu", Recueil des Cours de la Académie de Droit International, t. 280, 1999, p. 150. Por el contrario, en el derecho internacional humanitario, incluso durante el derecho internacional clásico, el interés hacia el individuo se centra en la posición que ocupa en el conflicto armado y no como elemento integrante de la población del Estado.

7 Pastor Ridruejo, José Antonio, op. cit., nota 2, p. 187.

8 Entre los más importantes representantes de esta teoría tenemos a Anzilotti y Triepel. Cfr. Novak, Fabián y García-Corrochano, Luis, Derecho internacional público, t. II, vol. 2, Lima, Pontificia Universidad Católica del Perú-Instituto de Estudios Internacionales, 2002, p. 214. 
no. ${ }^{9}$ Pese a esta posición dominante, expresada también a través de la jurisprudencia de la Corte Permanente de Justicia Internacional, ${ }^{10}$ existieron en el derecho internacional clásico algunos autores ${ }^{11}$ que reconocían la personalidad jurídica internacional del individuo, y por ende, la titularidad efectiva de derechos y obligaciones internacionales.

No debemos dejar de mencionar que en el derecho internacional clásico se reconocía junto a los Estados a otras entidades ${ }^{12}$ como poseedoras de un cierto nivel de subjetividad jurídica internacional. Asimismo, es en el transcurso del siglo XIX al siglo XX que se producen las primeras convenciones de derecho internacional humanitario, ${ }^{13}$ las cuales fueron pioneras al expresar la preocupación internacional por la suerte de los seres humanos en conflictos armados, reconociendo al individuo como beneficiario directo de las obligaciones convencionales estatales.

9 Otra tesis fue la del hombre-objeto, según la cual el ser humano es un objeto del derecho internacional, al igual que las aeronaves o navíos. Esta tesis fue formulada por Heilborn en 1896 y continuada por Arangio-Ruiz, Sereni y Quadri, entre otros. Cfr. idem.

10 "It may be readily admitted that, according to a well established principle of international law, the Beamtenabkommen [un tratado entre Polonia y Alemania] being an international agreement, cannot, as such, create direct rights and obligations for private individuals. But it cannot be disputed that the very object of an international agreement, according to the intention of the Contracting Parties, may be the adoption by the Parties of some definitive rules creating individual rights and obligations enforceable by the national courts". Corte Permanente de Justicia Internacional, Opinión Consultiva relativa al asunto de los Oficiales Ferroviarios de Danzing del 3 de marzo de 1928, serie B, núm. 15 , parágrafos 17 y 18 .

11 Entre los cuales tenemos a: Heffter, Pillet, Rougier, Fiore, Spiropoulos, Scelle. Citados por Cançado, Antonio, "El Reglamento de la Corte Interamericana de Derechos Humanos (2000) y su proyección hacia el futuro: La emancipación del ser humano como sujeto de derecho internacional", en Cançado, Antonio y Manuel, Ventura (eds.), El futuro de la Corte Interamericana de Derechos Humanos, San José, Corte Interamericana de Derechos Humanos-Alto Comisionado de las Naciones Unidas para los Refugiados, 2004, pp. 64 y ss.

12 Como la Santa Sede y los grupos rebeldes con estatuto de beligerancia. Sobre el particular, cfr. Barberis, Julio, Los sujetos del derecho internacional actual, Madrid, Tecnos, 1984, pp. 97 y ss.

13 Así tenemos la Convención de Ginebra para el Mejoramiento de la Suerte de los Militares Heridos en los Ejércitos en Campaña del 22 de agosto de 1864; la Convención de la Haya del 29 de julio de 1899 y su reglamento; la Convención relativa a las Leyes y Costumbres de la Guerra Terrestre del 18 de octubre de 1907 y su reglamento. 


\section{Situación del individuo en el derecho internacional contemporáneo}

Una aproximación analítica a la evolución del derecho internacional nos señala una tendencia cada vez mayor, relativa a la ampliación del círculo de los sujetos de derecho internacional que ha conducido a una renovación cuantitativa del derecho internacional. Lo anterior está dado por la expansión del ámbito objetivo del ordenamiento jurídico internacional, así como por una proliferación de los sujetos participantes, ${ }^{14}$ entre los que el individuo como sujeto de derecho internacional merece en la actualidad especial importancia.

Dos actos jurídicos internacionales fueron especialmente relevantes para el cambio de la situación de la subjetividad jurídica internacional, en general, y de la subjetividad jurídica internacional del individuo, en particular. Nos referimos a la sentencia del Tribunal Militar Internacional de Nüremberg ${ }^{15}$ y a la opinión consultiva de la Corte Internacional de Justicia (CIJ) sobre la reparación de daños sufridos al servicio de la Organización de Naciones Unidas (ONU). ${ }^{16}$

Respecto a la primera, podemos decir que, desde el juzgamiento de los individuos por los crímenes internacionales cometidos por miembros del Eje durante la Segunda Guerra Mundial, se consideró necesario reconocer la subjetividad jurídica internacional individual. Ello hizo factible no sólo la protección directa y efectiva de los derechos humanos, sino y sobre todo, la posibilidad de ser sancionado como resultado del reconocimiento de la responsabilidad internacional individual por violaciones graves de obligaciones internacionales. La sentencia del Tribunal de Nüremberg refutó el punto de vista del positivismo extremo, el cual señalaba que el derecho internacional sólo era aplicable a los Estados. Esta sentencia también demostró que los individuos podían ser encontrados culpables por crímenes bajo el derecho internacional y podían ser sancionados de acuerdo a su capacidad personal. En tal sentido, es de gran importancia el siguiente pasaje de la sentencia del Juicio de Nüremberg:

14 Diez de Velasco, Manuel, Instituciones de derecho internacional público, 13a. ed., Madrid, Tecnos, 2001, p. 215.

15 Tribunal Militar Internacional de Nüremberg, Francia y otros $v$. Goering y otros, sentencia del 30 de septiembre-1o. de octubre de 1946.

16 CIJ, Opinión Consultiva sobre Reparación de Daños Sufridos al Servicio de las Naciones Unidas del 11 de abril de 1949. 
"Crimes against international law are committed by men, not by abstract entities, and only by punishing individuals who commit such crimes can the provisions of international law be enforced". ${ }^{17}$

Respecto a la opinión consultiva citada, debido a la percepción de la existencia de sujetos de derecho internacional distintos al Estado - por imperio de la realidad de la comunidad internacional - aportó que, con la evolución del derecho internacional, el individuo adquiera en la actualidad subjetividad jurídica internacional. En tal sentido, la CIJ señaló que:

The subjects of law in any legal system are not necessarily identical in their nature or in the extent of their rights, and their nature depends upon the needs of the community. Throughout its history, the development of international law has been influenced by the requirements of international life, and the progressive increase in the collective activities of States has already given rise to instances of action upon the international plane by certain entities which are not States. ${ }^{18}$

Este dictum no define qué clase de entidades pueden ser sujetos de derecho internacional o qué derechos y deberes tienen. Sin embargo, un elemento implícito en la definición se refiere a las condiciones de subjetividad jurídica internacional que deben derivarse de una regla que proporcione el criterio para el reconocimiento de la subjetividad. ${ }^{19}$

En este contexto, se incorporó en la subjetividad jurídica internacional del individuo la temática de la responsabilidad internacional individual, de manera paralela a la responsabilidad internacional del Estado. ${ }^{20}$ De este modo, "siendo el individuo sujeto de deberes en el plano del de-

17 Tribunal Militar Internacional de Nüremberg, Francia y otros $v$. Goering y otros, sentencia del 30 de septiembre-1o. de octubre de 1946, p. 221.

18 CIJ, Caso concerniente a la Reparación por Daños Sufridos al Servicio de las Naciones Unidas, Opinión Consultiva del 11 de abril de 1949, p. 179.

19 Sunga, Lyal, Individual Responsibility in International Law for Serious Human Rights Violations, Dordretch-Boston-London, Martinus Nijhoff Publishers, p. 141.

20 La doctrina jurídica jusinternacionalista desde mediados del siglo XX reflejó el proceso de evolución histórica-jurídica relativo a la emancipación de los individuos de la tutela exclusiva del Estado. Los acontecimientos acaecidos refutaban la teoría que consideraba a los individuos como meros objetos del ordenamiento jurídico internacional, así como otros conceptos del positivismo jurídico estatal. 
recho internacional, no más no había como negar su personalidad jurídica internacional consuetudinaria". ${ }^{21}$

En la afirmación de la subjetividad del individuo en el plano internacional, ha contribuido el desarrollo tanto del derecho penal internacional como del derecho internacional de los derechos humanos y el internacional humanitario. ${ }^{22}$ Las transformaciones experimentadas en las últimas décadas por el derecho internacional han originado que se reconozca un cierto grado de subjetividad jurídica internacional del individuo.

Como ha señalado Carrillo Salcedo, ${ }^{23}$ esta situación de cambio es atribuible a tres fenómenos que se interrelacionan: un proceso de institucionalización, un proceso de socialización y un proceso de humanización. El hito histórico inicial de este proceso de humanización se sitúa hacia el final de la Segunda Guerra Mundial. En esta etapa se dio la convergencia de dos inquietudes. Por un lado, la postura a favor de la protección de los derechos humanos. Por otro lado, la desaprobación consensual de los métodos y medios de preparación de la guerra y su conducción; lo cual se encuentra relacionado con la noción de crímenes de derecho internacional y la generación de responsabilidad internacional del individuo por la realización de dichas conductas.

No obstante, debemos tener en cuenta que la subjetividad jurídica internacional del individuo es todavía hoy reducida y limitada. Como ya afirmáramos, la práctica internacional contemporánea reconoce un determinado nivel de subjetividad internacional del ser humano, al igual que la existencia de normas que imponen obligaciones jurídicas a los individuos. Pese a lo afirmado, en ambos casos se tratan de ejemplos concretos y limitados que no permiten defender la tesis de la plena subjetividad jurídica internacional individual. ${ }^{24}$ La subjetividad jurídica internacional del individuo se encuentra determinada por el derecho internacional. De

21 Cançado, Antonio, op. cit., nota 11, p. 66.

22 Este último considera a las personas protegidas no sólo como un mero objeto, sino por el contrario como verdaderos sujetos de derecho internacional. Lo anterior se desprende de las normas de los cuatro Convenios de Ginebra sobre Derecho Internacional Humanitario de 1949. Así tenemos: Convenio III, artículos 14 y 78; Convenio IV, artículo 27.

23 Carrillo Salcedo, Juan Antonio, "Droit international et souveraineté des Etats", en Recueil des Cours de la Académie de Droit International, vol. 257, 1996-I, pp. 212 y ss.

24 Rueda, Casilda, Delitos de derecho internacional. Tipificación y represión internacional, Barcelona, Bosch, 2001, pp. 25-28. 
ahí que el rol que pueda asumir el individuo en el derecho internacional depende del nivel de subjetividad que se le pueda reconocer. ${ }^{25}$

El derecho internacional contemporáneo se encuentra en un proceso de paulatina humanización; por lo que se ha agregado a las funciones relacionales y competenciales ${ }^{26}$ la del desarrollo pleno de los individuos, lográndose una institucionalización en la materia. ${ }^{27}$ De conformidad con lo antes expuesto, hoy se reconoce, junto a la subjetividad jurídica internacional del Estado, entre otras manifestaciones de la subjetividad, la de las organizaciones internacionales, y que en situaciones específicas se afirme la subjetividad jurídica internacional del individuo. ${ }^{28}$

Nosotros consideramos que el individuo está, en varios casos, directamente implicado por el derecho internacional, y que posee una subjetividad jurídica internacional limitada, que ha sido reconocida ya sea por el derecho internacional convencional o el derecho internacional consuetudinario. Pero la característica de limitada no impide que el individuo sea sujeto de derecho internacional. Igualmente, el contacto directo del individuo con el derecho internacional se ha intensificado a partir de la últi-

25 Algunos autores prefieren distinguir entre capacidad jurídica y capacidad de obrar del individuo. La primera se refiere a los derechos internacionales de la persona, mientras que la segunda alude a la posibilidad de cierta actuación con relevancia internacional del ser humano. Siguiendo lo anterior, tenemos, en palabras de Rueda, que "La capacidad de obrar puede ser tanto activa como pasiva: sería activa cuando la misma persona tuviera competencias para hacer valer sus derechos en la esfera internacional; sería pasiva cuando la relevancia internacional de sus actuaciones apuntara a la idea de ser tenida como internacionalmente responsable por la comisión de hechos ilícitos". Ibidem, p. 28.

26 Pastor Ridruejo identifica como características del derecho internacional contemporáneo el ser un ordenamiento jurídico de carácter social, institucionalizado y democrático. Pastor Ridruejo, José Antonio, op. cit., nota 2, p. 61. En conexión con lo señalado, Dupuy identifica como caracteres generales de la comunidad (sociedad en términos de Dupuy) internacional dos combinaciones de características aparentemente antagónicas. De una parte, la comunidad internacional es interdependiente pero descentralizada, y por otro lado conflictiva pero a la vez deliberante. $C f r$. Dupuy, Pierre-Marie, Droit International Public, París, Dalloz, 1998, pp. 1 y ss.

27 Debemos considerar que pese a las transformaciones que se suscitan en el derecho internacional, la comunidad internacional aún se caracteriza por la preeminencia de los Estados. Asimismo, se admite que un tratado puede crear (según las circunstancias) directamente derechos y obligaciones para los individuos si ello corresponde con la intención de los Estados partes.

28 O como señala Pastor Ridruejo, la subjetividad jurídica internacional de los particulares, personas físicas o jurídicas. Cfr. Pastor Ridruejo, José Antonio, op. cit., nota 2, p. 187. Incluso se discute la subjetividad jurídica internacional de los pueblos. 
ma conflagración mundial. En tal sentido, compartimos la opinión de Cassese en torno a la situación del individuo en el derecho internacional contemporáneo:

Individuals possess international legal status. They have a few obligations, deriving from customary international law. In addition, procedural rights ensure to the benefit of individuals, not however vis-à-vis all States, but only towards the group of States that have concluded treaties, or the international organizations that have adopted resolutions, envisaging such rights. Clearly, the international legal status of individuals is unique: they have a lopsided position in the international community. ${ }^{29}$

Lo afirmado, en último lugar, también coincide con la aparición del sector llamado "comunitario" o "público" en aquel orden jurídico. En tal sentido, al crecer la importancia del papel comunitario crece también la importancia del individuo, y "las entidades intermedias entre individuos y la comunidad, que son los Estados, en cierta medida ven su propia esfera de acción limitada y encogida". ${ }^{30}$

\section{Teorías sobre la situación del individuo en el derecho internacional}

Posición doctrinal clásica. En la teoría del derecho natural de Groccio, el ser humano es un punto focal de todo el derecho, incluyendo el derecho internacional o "derecho de las naciones". Los sucesores de Groccio, en especial Vattel, pusieron mayor énfasis en el Estado como titular de derechos y obligaciones en el contexto internacional, en el ámbito de validez del derecho natural. En la teoría del derecho internacional de Vattel, los individuos no son considerados como sujetos directos del "derecho de las naciones". Vattel postula una dicotomía entre el derecho natural el cual gobierna al individuo en el derecho nacional, y el "derecho de las naciones" el cual deriva del derecho natural, pero que se aplica sólo a los Estados en sus relaciones mutuas. Desde esta perspectiva, el individuo podría afirmar derechos naturales frente al Estado en un nivel interno, pero es simplemente un objeto y no un sujeto del "derecho de las

\footnotetext{
29 Cassese, Antonio, op. cit., nota 1, p. 150.

30 Barboza, Julio, Derecho internacional público, Buenos Aires, Zavalia, 1999, p. 589.
} 
naciones". ${ }^{31}$ La dicotomía existente entre el derecho internacional, en el cual sólo los Estados son los únicos sujetos, y el derecho nacional, constituye una premisa importante en la influyente doctrina del positivismo legal. ${ }^{32}$

Posición kelseniana ${ }^{33}$ La teoría pura del derecho elaborada por Hans Kelsen vincula la noción de sujeto de derecho internacional con el ámbito de validez personal de la norma jurídica internacional; lo cual implica que se obtendrá esta subjetividad si es que se poseen derechos y obligaciones jurídicas internacionales directos. Es decir, según los seguidores de la teoría pura del derecho, es suficiente que una norma jurídica prevea una conducta suya como contenido de un derecho o de una obligación. La concepción monista kelseniana organiza el derecho internacional y el derecho interno en una jerarquía en la cual el derecho internacional se encuentra en la cima, ${ }^{34}$ sin hacer una división en dos planos separados. El punto de partida de la teoría de Kelsen es el ser humano, más que el Estado. ${ }^{35}$ Según esta teoría las normas del derecho internacional, al igual que cualquier norma jurídica, regulan conductas humanas aunque lo hacen de modo directo o indirecto. En tal sentido, la teoría pura considera como sujeto de derecho internacional al individuo ( $u$ otra entidad) que sea destinatario directo de dicho orden jurídico. Kelsen estima que existen situaciones en las que la conducta de un individuo es regulada directamente por el orden internacional como permitida, prohibida u obligatoria. En tal sentido, Kelsen sostiene que: "Il y a en effet en droit interna-

31 Ibidem, pp. 150 y 151.

32 Elaborada por Hobbes, Bentham, Austin, y H. L. A. Hart. Cfr. Sunga, Lyal, op. cit., nota 19, p. 150.

33 Para mayores detalles de la aplicación de esta teoría al concepto de sujeto de derecho internacional, en general cfr. Barberis, Julio, op. cit., nota 12, pp. 20 y ss.

34 Cabe mencionar que para Kelsen la "norma fundamental" del sistema podía ser el ordenamiento estatal (monismo con primacía del derecho interno) o el internacional (monismo con primacía del derecho internacional), aunque desde 1934 se inclinó hacia la superioridad del derecho internacional. Cfr. Gonzáles Campos, Julio et al., Curso de Derecho Internacional Público, Madrid, Servicio de Publicaciones de la Universidad Complutense, 1992, p. 222.

35 "Like all law, international law, too, is a regulation of human conduct. It is to men that the norms of international law apply; it is against men that they provide sanctions; it is to men that they entrust the competence of creating the norms of the order". Kelsen, Hans, Principles of International Law, 2a. ed., Nueva York, Holt, Riehart \& Winston, 1960, p. 180. Citado por Sunga, Lyal, op. cit., nota 19, p. 150. 
tional des normes déterminant directement l'individu qui par sa propre conduite peut commettre ou s'abstenir de commettre un acte illicite... Il y a des normes du droit international et notamment des normes conventionnelles qui autorisent des personnes privées à porter plainte contre un Etat". 36

Sin embargo, en la mayoría de los casos no se da tal supuesto, toda vez que el derecho internacional se refiere directamente a entidades tales como los Estados u organizaciones internacionales. A su vez, los ordenamientos jurídicos de tales entidades se refieren de manera directa a los individuos, por lo que, en estos casos, los individuos son regidos de manera indirecta por el derecho internacional. ${ }^{37} \mathrm{La}$ subjetividad jurídica internacional del individuo sería una excepción. ${ }^{38}$

Teoría de la responsabilidad internacional del individuo. Para los seguidores de esta teoría se considera sujeto de derecho internacional a todo aquél que se encuentra por lo menos en una de las dos siguientes posibilidades (no necesariamente en ambas, como la teoría anterior): a) La titularidad de un derecho, y a la vez la posibilidad de hacerlo valer mediante reclamación internacional; b) La titularidad de una obligación jurídica internacional y la capacidad de ser sujeto pasivo de reclamación ante un tribunal internacional, es decir ser destinatario de una sanción internacional. ${ }^{39}$ En tal sentido, según esta teoría, la posesión por una entidad de la titularidad de modo efectivo de un derecho o de una obligación en el contexto internacional, origina la calificación como sujeto de derecho internacional. La subjetividad y la responsabilidad internacional del individuo estarían así vinculadas, tal y como lo expuso en su momento

36 Kelsen, Hans, "Théorie du Droit International Public", Recueil des Cours de la Académie de Droit International, vol. 84, 1953-III, pp. 93 y 96.

37 "Le droit international détermine de façon seulement indirecte les individus qui doivent se conduire de la manière prescrite et qui, s'ils s'en abstiennent, commettent un acte illicite imputable à l'Etat. Il délègue au droit national le soin de désigner ces individus". Ibidem, p. 87.

38 Ibidem, p. 93. Sunga agrega, al reseñar esta teoría lo siguiente: "International law would have to become like municipal law requiring the appearance of a world State for individual subjectivity under international law to be the general norm, concludes Kelsen". Sunga, Lyal, op. cit., nota 19, pp. 150 y 151.

39 Cfr. Barberis, Julio, op. cit., nota 12, pp. 22-24. Se debe considerar que mientras que la dimensión activa de la subjetividad del individuo es excepcionalmente prevista por el derecho internacional convencional, la responsabilidad internacional del individuo por la comisión de crímenes viene dada fundamentalmente por el DI consuetudinario. 
Eusthatiades: "On voit par là liaison étroite existante entre la responsabilité internationale et le problème des sujets du droit international. L'individu n'apparaîtra comme sujet immédiat du droit international que dans le cas où sa responsabilité personnelle sera engagée sur le plan international". ${ }^{40}$

Se debe precisar que Wengler, quien desarrolló la teoría de la responsabilidad, a diferencia de Eustathiades, estableció una distinción básica entre el acto ilícito (delito), de un lado, y la responsabilidad, del otro lado. En este sentido, el acto ilícito es la condición de una sanción, mientras la responsabilidad consiste en ser el destinatario de esa sanción, independientemente del hecho que se haya sido autor o no del acto ilícito. ${ }^{41}$

Teoría del destinatario directo y efectivo de un derecho o de una obligación internacional. Según esta teoría, ${ }^{42}$ la calidad de sujeto de derecho internacional (lo que incluye al individuo) no depende de la cantidad de derechos u obligaciones internacionales. Entonces, si el individuo es titular de un derecho o de una obligación internacional, será sujeto de derecho internacional. Asimismo, de acuerdo a esta posición, la subjetividad no está determinada por el tipo de derecho u obligación que se po-

40 Eusthatiades, Constantin, "Les sujets du droit international et la responsabilité international. Nouvelles tendances", Recueil des Cours de la Académie de Droit International, vol. 84, 1953-III, p. 412.

41 Como agrega Barberis: "Esta distinción es importante, pues hay casos donde no existe identidad entre el autor del acto ilícito y el destinatario de la sanción. [Wengler] también analiza el derecho de la guerra y estima que todo individuo o comunidad que sea objeto de una sanción en este ámbito, es sujeto de derecho internacional. Wengler generaliza luego este análisis y llega a la conclusión que sujeto de derecho de gentes es quien es responsable internacionalmente, o sea, todo aquel que puede ser destinatario de una sanción internacional". Barberis, Julio, op. cit., nota 12, p. 24. Dentro de esta posición, también podemos citar a Ian Brownlie. Cfr. Brownlie, Ian, Principles of Public International Law, Oxford, Clarendon Press, 1990, p. 58. Sin embargo, a diferencia de Eusthatiades y Wengler, Brownlie exige para la atribución de subjetividad jurídica internacional la acumulación de titularidad de derechos y obligaciones: "A subject of the law is an entity capable of possessing international rights and duties and having the capacity to maintain its rights by bringing international claims".

42 Sostenida entre otros por Carrillo Salcedo y por Julio Barberis. Este último define expresamente como sujeto de derecho internacional a: "aquél cuya conducta esta prevista directa y efectivamente por el derecho de gentes como contenido de un derecho o de una obligación... [asimismo, sostiene que] aquí se habla de obligación jurídica y no de responsabilidad. Quien asume efectivamente una obligación es quien cumple la prestación, $\mathrm{y}$, en caso de incumplimiento, paga las indemnizaciones, intereses o perjuicios correspondientes". Barberis, Julio, op. cit., nota 12, p. 26. 
sea, debido a la pluralidad existente de sujetos de derecho internacional, uno de los cuales es el ser humano. Además de lo señalado hasta ahora, coincide con la anterior postura, en exigir que el titular del derecho u obligación lo sea de manera efectiva. La diferencia radica en que exige que el titular del derecho u obligación internacional (en este caso el individuo) lo sea también de manera directa. Lo anterior significa que si en un tratado aparece una entidad como titular de los derechos u obligaciones señalados en sus normas, pero ellos son ejercidos por otra entidad que no aparece en el texto convencional, la última tendrá la auténtica subjetividad jurídica internacional. ${ }^{43}$

Aproximaciones empíricas. Varios autores adoptan una aproximación empírica para explicar las manifestaciones de subjetividad jurídica internacional del individuo (y de otras entidades no estatales) referente al grado de derechos, deberes y capacidad procesal que posee en el derecho internacional. Esas explicaciones tienen como punto de partida el reconocimiento de la existencia de instancias de capacidad legal individual. De acuerdo a Oppenheim, el derecho internacional es básicamente un derecho entre Estados, por lo que los Estados serían los únicos sujetos de derecho internacional. Según este autor la posición normal del individuo es la de un objeto, más que la de un sujeto de derecho internacional. ${ }^{44}$ No obstante, él afirma que los acontecimientos posteriores a la Segunda Guerra Mundial no justifican más la opinión que, en el derecho internacional, los Estados sean los únicos sujetos de derecho internacional. Y por ello se debe incrementar la disposición para tratar a los individuos como sujetos de derecho internacional (aunque en una esfera limitada). ${ }^{45}$

De acuerdo a lo señalado por Jessup, ${ }^{46}$ el derecho internacional es un derecho aplicable a los Estados en sus relaciones mutuas y también a los

43 Para un desarrollo más amplio de esta teoría véase ibidem, pp. 24-26. Entre otros aspectos se señala (frente a la pregunta de qué se entiende por destinatario directo de una norma internacional que otorga un derecho o impone una obligación) que el titular de un derecho u obligación puede no ser quién figura como tal en la letra de un tratado.

44 No obstante, Oppenheim sostiene que los individuos pueden subsidiariamente obtener subjetividad por un tratado y ser considerados sujetos normales de derecho internacional. Cfr. Meron, Theodor, "Général Course on Public International Law", Recueil des Cours de la Académie de Droit International, t. 301, 2003, p. 327.

45 Lauterpacht, Hersch, Oppenheim's International Law, 8a. ed., Londres, Longman, 1962, t. I, p. 639. Citado por idem.

46 Jessup, Philip, A Modern Law of Nations, Nueva York, Macmillan, 1948. Cfr. Sunga, Lyal, op. cit., nota 19, p. 154. 
individuos en sus relaciones con los Estados. Bajo este planteamiento, el derecho internacional podría también aplicarse a las relaciones entre individuos, siempre que impliquen materias de derecho internacional. ${ }^{47}$

Finalmente Lauterpach ${ }^{48}$ sostiene que la capacidad procesal del individuo bajo ciertos tratados permite concluir que los Estados no son los únicos sujetos de derecho internacional de acuerdo a la práctica internacional. En tal sentido, plantea que en el derecho internacional la capacidad para demandar o ser demandado ante una instancia internacional no debería considerarse como un factor determinante para establecer la subjetividad jurídica internacional de una determinada entidad (en el caso particular, el individuo). ${ }^{49}$

47 Tomado fuera de contexto, aparentemente Jessup reconoce al individuo como un sujeto de derecho internacional. Sin embargo, él es de la opinión que en tanto la comunidad internacional está compuesta por Estados, una norma jurídica internacional no se aplica directamente al individuo excepto por normas convencionales (tratados). $\mathrm{O}$ en todo caso, de acuerdo a lo establecido por una autoridad internacional cuyo poder proviene de los Estados. Cfr. idem.

48 "The fact that the beneficiary of rights is not authorized to take independent steps in his own name to enforce them does not signify that he is not subject of the law... it is no longer possible, as a matter of positive of law, to regard Status as the only subjects of international law, and there is an increasing disposition to treat individuals, within a limited sphere, as subjects of international law". Lauterpacht, Hersch, op. cit., nota 45.

49 Entre otras aproximaciones al tema, tenemos a la doctrina tradicional soviética, la cual considera que el derecho internacional es un derecho cuyos únicos sujetos son los Estados. El derecho internacional sería el conjunto de normas que gobiernan las relaciones entre los Estados. La noción de otras entidades no estatales como sujetos entra en conflicto con esta definición. Ésto no implica plantear que el individuo no puede ser encontrado responsable bajo el derecho internacional. En esta perspectiva, el individuo puede ser encontrado responsable bajo el derecho internacional como sucedió en los juicios de Nüremberg y Tokio; sin embargo, el individuo no es reconocido como un sujeto pleno de derecho internacional. Algunos autores de esta corriente (como Tunkin), sostienen que nuevos sujetos de derecho internacional han surgido como organizaciones internacionales y pueblos que luchan por su independencia. También resaltan que la responsabilidad del individuo ha emergido como una nueva e importante institución del derecho internacional frente a los crímenes de derecho internacional, de acuerdo a la definición de la sentencia y juicio de Nüremberg. De acuerdo con Verdross, un individuo es un sujeto de derecho internacional, sólo si es posible para él ser directamente responsable. Guggenheim, por su lado, establece una distinción entre los sujetos directos e indirectos. Spiropoulus, quien considera la subjetividad jurídica internacional como una materia conceptual más que empírica, señala que un sujeto de derecho internacional es al cual las órdenes judiciales se dirigen inmediatamente. Para Korowicz es suficiente que el individuo tenga un solo derecho de petición para calificar como sujeto. García Amador desinte- 


\section{DIMENSIÓN ACTIVA. TITULARIDAD EFECTIVA DE DERECHOS ${ }^{50}$}

\section{Aspectos generales}

Esta dimensión de la subjetividad jurídica internacional del individuo implica que el ser humano puede reclamar de manera directa ante una instancia internacional por la vulneración de sus derechos y sin la

gra el concepto de "sujeto legal" en sujeto de derechos y sujeto de procedimientos y concluye a partir del hecho que el derecho internacional protege derechos e intereses de entidades no estatales, que los Estados no son los únicos sujetos de derecho internacional. De acuerdo a León Duguit (seguido por Georges Schelle en derecho internacional), el derecho se aplica a seres concientes más que a entidades abstractas. El derecho puede aplicarse, por lo tanto, sólo a los individuos, los cuales serían los únicos sujetos de derecho internacional; sin gozar de tal calidad los Estados. Las referencias de esta cita pueden encontrarse en Sunga, Lyal, op. cit., nota 19, pp. 151 y ss.; y Diez de Velasco, Manuel, op. cit., nota 14, pp. 250 y 251.

50 Las dimensiones de la subjetividad jurídica internacional (activa y pasiva) se complementan con las figuras de refugio, asilo y extradición. Sobre el tema de la extradición podemos señalar que es uno de los instrumentos más importantes de cooperación jurídica entre los Estados en materia penal. Supone la entrega de un fugitivo de la justicia de un Estado a otro que pretende su enjuiciamiento por causa penal o dar cumplimiento a la ejecución de una sentencia condenatoria privativa de libertad. Como características tenemos: a) Base convencional; b) Doble incriminación (sólo por hechos que son delictivos tanto en el Estado que solicita la extradición como en el llamado a concederla); c) Al extraditarlo, sólo se puede juzgar por el motivo o los motivos que se concedió la extradición y d) No procede por motivos políticos. La definición de refugiado se encuentra en el artículo 1.A. 2) de la Convención sobre el Estatuto de Refugiado del 28 de julio de 1951: "[es refugiado toda persona que] debido a fundados temores de ser perseguida por motivos de raza, religión, nacionalidad, pertenencia a determinado grupo social u opiniones políticas, se encuentre fuera del país de su nacionalidad y no pueda o a causa de dichos temores no quiera acogerse a la protección de tal país; o que, careciendo de nacionalidad y hallándose, a consecuencia de tales acontecimientos, fuera del país donde antes tuviera su residencia habitual, no pueda o, a causa de dichos temores, no quiera regresar a él". Los rasgos de esta figura son: a) Una ruptura de la relación de confianza entre el solicitante de refugio y su Estado de nacionalidad o residencia habitual y b) El cruce de frontera. Finalmente, en el caso del asilo, a partir de la Declaración de asilo territorial de la ONU de 1967 se reconocen como rasgos del derecho de asilo: a) Derecho del Estado a concederlo; b) Derecho del individuo a buscarlo y c) Principio de no devolución del solicitante de asilo al Estado que lo persigue. En Latinoamérica también se reconoce la figura de asilo diplomático. Para más detalles véase respectivamente Remiro Brotóns, Antonio et. al., Derecho internacional, Madrid, Mc-Graw Hill, 1997, pp. 494-498, 1008-1010; 1011-1015. 
necesidad de la intermediación de otras entidades. El estado actual de desarrollo del derecho internacional indica que el individuo carece de plena capacidad procesal en la reclamación de sus derechos ante las instancias internacionales. No obstante, se ha ido desarrollando este aspecto observando lo dispuesto por las normas convencionales o mediante la implementación de mecanismos en determinadas organizaciones internacionales, que progresivamente se han dado. En términos de Cassese, la dimensión activa de la subjetividad jurídica internacional individual está constituida por "procedural rights ensure to the benefit of individuals, not however vis-à-vis all States, but only towards the group of Status that have concluded treaties, or the international organizations that adopted envisaging such rights". ${ }^{51}$

Como primeros hitos tenemos a la Convención XII de la Segunda Conferencia de Paz de la Haya ${ }^{52}$ que creó un Tribunal Internacional de Presos. Este tribunal fue diseñado para admitir las reclamaciones de ciertos individuos con nacionalidad de un Estado beligerante o neutral. También tenemos a la extinta Corte de Justicia Centroamericana, ${ }^{53}$ que poseía la facultad para recibir demandas de individuos, luego del agotamiento de los recursos internos, y que llegó a conocer cinco casos. ${ }^{54}$

En el periodo de entreguerras, se produce la creación de Tribunales Arbitrales Mixtos, como en el caso de la Primera Guerra Mundial entre las potencias aliadas y asociadas y Alemania, por los tratados de paz, ${ }^{55}$

51 Cassese, Antonio, op. cit., nota 1, p. 150.

52 Convención XII de la Segunda Conferencia de Paz de la Haya del 18 de octubre de 1907. En específico, su artículo 4o. No obstante, se debe mencionar que esta Convención nunca entró en vigor.

53 Esta Corte creada en 1908 fue disuelta en 1918, al quedar demostrado que los Estados miembros no estaban realmente preparados para permitir el acceso de individuos a la jurisdicción internacional. Cfr. Cassese, Antonio, op. cit., nota 1, p. 147.

54 Los casos fueron: el asunto Fornos, el asunto Molina Lartos, el asunto Cerda, el asunto Bermúdez y el asunto del presidente González Flores. Estos casos fueron rechazados por no haber agotado las vías internas. Citados por Novak, Fabián y García-Corrochano, Luis, op. cit., nota 8, p. 220.

55 Así tenemos el Tratado de Versalles del 18 de junio de 1919, el Tratado de Saint Germain del 10 de septiembre de 1919, el Tratado de Neuilly del 27 de noviembre de 1919, el Tratado de Trianón del 4 de junio de 1920 y el Tratado de Lausana de 1923. 
donde los individuos podían presentar reclamaciones. ${ }^{56}$ Otro ejemplo, en la era de la Sociedad de las Naciones, fueron los sistemas de las minorías. En este caso, una de las vías procesales se sustanciaba por el derecho concedido a los miembros de las minorías lesionadas de llevar sus peticiones ante la Secretaría de la Sociedad de las Naciones. ${ }^{57}$

Tales antecedentes precedieron al desarrollo de la dimensión activa de la subjetividad jurídica del individuo en el plano internacional, cuyo avance se dio de manera notable luego de la Segunda Guerra Mundial. Esta evolución se reflejó de manera especial en el progreso del sistema universal y de los sistemas regionales de protección de derechos humanos.

En este punto nos parece relevante hacer una referencia general a la situación del individuo en el derecho interno de las organizaciones internacionales. En esta dimensión, los tribunales administrativos del sistema de la $\mathrm{ONU}^{58}$ son un claro ejemplo de la posibilidad que tienen los individuos de acceder a una instancia internacional en reclamación de sus derechos. ${ }^{59}$ En su opinión consultiva sobre la reparación de los daños sufridos al servicio de la Organización, la CIJ define a los agentes internacionales del siguiente modo: "The Court understands the word 'agent' in the most liberal sense, that is to say, any person who, whether a paid official or not, and whether permanently employed or not, has been charged by an organ of the Organization with carrying out, or helping to carry out, one of its functions-in short, any person through whom it acts". ${ }^{60}$

56 Alegando daños sufridos debido a las acciones u omisiones del Estado demandado o a litigios concluidos entre los nacionales de las partes en conflicto antes que los tratados de paz entren en vigor. Véase Diez de Velasco, Manuel, op. cit., nota 14, p. 252.

57 Ésta evaluaba su admisibilidad, siendo necesario un pronunciamiento del Consejo de la Sociedad de Naciones en el supuesto de oposición por parte del Estado interesado. Otros ejemplos fueron los territorios bajo mandato, los sistemas de peticiones de la Alta Silesia, las islas Aaland, del Sarre y de Danzig, así como las comisiones mixtas de reclamaciones. Cfr. idem.

58 El Tribunal de la ONU y el Tribunal de la Organización Internacional del Trabajo son los que tienen mayor carga procesal. El Banco Mundial y el Fondo Monetario Internacional tienen sus propios tribunales. Cfr. Barboza, Julio, op. cit., nota 30, p. 595.

59 Estos tribunales consideran las demandas de los individuos que laboran en las entidades del sistema mencionado. Cfr. ibidem.

60 CIJ, Caso concerniente a la Reparación por Daños Sufridos al Servicio de las Naciones Unidas, Opinión Consultiva del 11 de abril de 1949, p. 177. 
Las reglas de la Asamblea General de la ONU y las reglamentaciones generadas por el secretario general rigen las relaciones entre los agentes internacionales y la organización internacional. A su vez, es la propia carta de la ONU, la fuente última de validez de estos tribunales. ${ }^{61}$

Por otro lado, en relación al derecho comunitario, el rol del individuo es mayor si lo comparamos con su papel en las organizaciones internacionales. El derecho comunitario es "superior al nacional y por ende origina derechos subjetivos que las autoridades locales deben respetar y proteger. Por ende, toda disposición contraria del derecho internacional se torna inaplicable". ${ }^{62}$

En el caso del derecho comunitario europeo, las personas físicas y jurídicas pueden dirigirse al Tribunal de Justicia de las Comunidades Europeas por medio de diferentes vías. ${ }^{63}$ Los reglamentos comunitarios que expiden el Consejo y la Comisión europeos se aplican directamente a los individuos de todos los Estados miembros. Por su parte, en el caso del derecho comunitario andino también se da la posibilidad que tienen las personas naturales de iniciar procesos ante el Tribunal de Justicia de la Comunidad Andina de Naciones. ${ }^{64}$ Finalmente, debemos señalar que los

61 Entonces, al ser la Carta de la ONU un tratado internacional, las normas de derecho interno de las organizaciones internacionales pertenecen al derecho internacional y rigen de manera excluyente frente a las normas del Estado, sede de la organización internacional.

62 Barboza, Julio, op. cit., nota 30, p. 371.

63 Se debe resaltar el recurso dirigido a obtener la anulación de las decisiones y otros actos de eficacia individual que les afecten directamente, y el recurso dirigido a exigir la responsabilidad extra-contractual de las comunidades europeas. Respectivamente, artículos 230 del Tratado de la Comunidad Económica Europea (CEE) y 146 del Tratado de la Comunidad Europea de Energía Atómica (CEEA), el artículo 235 del Tratado CEE, 151 del Tratado CEEA y artículo 40 del Tratado de la Comunidad Europea del Carbón y del Acero (CECA). Se debe recordar que a partir del Tratado de Maastricht del 7 de febrero de 1992, que crea la Unión Europea, la CEE, CEEA y CECA se han fusionado dando origen a la Comunidad Europea, uno de los tres pilares del proceso de integración europeo. Sobre este punto, cfr. Amerasinghe, Félix, Jurisdiction of International Tribunals, The Hague, Kluwer Law Internacional, 2003 (especialmente el capítulo 17 titulado "The Court of Justice of the European Communities", pp. 812 y ss.).

64 Así tenemos: acción de nulidad, acción de incumplimiento, recurso por omisión o inactividad, la función arbitral. Véase Tratado de Creación del Tribunal de Justicia de la Comunidad Andina modificado por el Protocolo Modificatorio del Acuerdo de Integración Subregional Andino (Acuerdo de Cartagena), Trujillo, 10 de marzo de 1996, artícu$\operatorname{los} 19,25,37$ y 38, respectivamente. Respecto al proceso de integración andino, se recomienda la lectura de varios autores, Derecho comunitario andino, Lima, Fondo Editorial 
seres humanos no tienen acceso a la CIJ ni en la vía contenciosa ni consultiva. ${ }^{65}$

\section{Subjetividad jurídica internacional del individuo en el ámbito de los derechos humanos}

\section{A. Sistema universal de protección de los derechos humanos}

La Declaración Universal de Derechos Humanos de la ONU66 constituye el texto básico para analizar los mecanismos de protección de la ONU, y por ende todos los demás textos se han inspirado en ella. ${ }^{67} \mathrm{~A}$ partir de ese momento, de manera progresiva se ha reconocido la capacidad del individuo de recurrir a la ONU y plantear sus quejas, en caso de la violación de sus derechos con la creación de mecanismos de supervisión al margen de la voluntad del Estado trasgresor.

Los sujetos de derecho internacional, tradicionalmente, han sido los Estados y las organizaciones internacionales, de ahí que la (ahora extinta) Comisión de Derechos Humanos de la $\mathrm{ONU}^{68}$ resolvió no poseer atribuciones para la adopción de medidas en las quejas individuales. ${ }^{69} \mathrm{Si}$

de la Pontificia Universidad Católica del Perú-Instituto de Estudios Internacionales, 2003.

65 Respectivamente, artículos 34 y 65 del Estatuto de la CIJ.

66 Declaración Universal de Derechos Humanos adoptada el 10 de diciembre de 1948 por Resolución de la Asamblea General 217 (III) de la ONU.

67 Como ejemplo de referencia a la Declaración Universal de los Derechos Humanos y a la naturaleza de sus normas, a nivel de jurisprudencia internacional, véase CIJ, Caso del Personal Diplomático y Consular de los Estados Unidos en Teherán, sentencia de méritos del 24 de mayo de 1980, parágrafo 91. Con respecto al carácter jurídico vinculante de las disposiciones de la Declaración Americana sobre Derechos Humanos, $c f r$. Corte IDH, Interpretación de la Declaración Americana de los Derechos y Deberes del Hombre en el Marco del Artículo 64 de la Convención Americana sobre Derechos Humanos, Opinión Consultiva OC-10/89 del 14 de julio de 1989, serie A, núm. 10.

68 Actualmente Consejo de Derechos Humanos de la ONU. Véase la Resolución de la Asamblea General de la ONU del 3 abril de 2006, A/RES/60/251.

69 Resolución 75-V de 1947. Citada por Garretón, Roberto, "La protección internacional de los derechos humanos. El sistema universal", XX Curso Interdisciplinario Rodolfo E. Piza Escalante, San José, Instituto Interamericano de Derechos Humanos, julio-agosto de 2002, ponencia; Mantilla, Julissa, Derechos humanos. Selección de textos, Lima, Pontificia Universidad Católica del Perú, 2004, p. 167. Como consecuencia, las quejas se agrupaban en la Secretaría General de la ONU sin solución, hasta que en 1959 
bien es cierto, la Comisión de Derechos Humanos reconoció que no estaba facultada para tomar alguna medida respecto a las reclamaciones relativas a derechos humanos, se consiguió que se distribuyera entre los Estados miembros de la Comisión una lista de las quejas recibidas. ${ }^{70}$

Como producto de las quejas, principalmente por el crimen de apartheid y las violaciones al Convenio IV de Ginebra de $1949^{71}$ se mejoró, aunque sólo ligeramente, el sistema en la Resolución 1503 del Ecosoc. ${ }^{72}$ Dicha resolución incorporó un mecanismo de estudio de las comunicaciones que parecían revelar una situación persistente de violaciones manifiestas y fehacientemente comprobadas de los derechos humanos y las libertades fundamentales. Desde ese momento, la Comisión de Derechos Humanos analizaría las situaciones sobre las que dan cuenta las comunicaciones. Aunque si bien las comunicaciones individuales activan el procedimiento "éste analiza la situación del país procurando verificar si ella corresponde a un cuadro persistente de violaciones de derechos humanos". 73

Por su parte los procedimientos "públicos" o de la Resolución 1235 del Ecosoc, ${ }^{74}$ no tienen ${ }^{75}$ un mandato expreso de conocer las comunicaciones individuales, aunque se entiende que se trata de una forma de atender quejas individuales. Ello debido a: la acumulación de quejas individuales; a que la información que piden los relatores surge, muchas veces, a partir de quejas individuales, y a que aquéllos, ante el conocimiento de una violación, dirigen una acción urgente al gobierno denunciado. ${ }^{76}$

Las reclamaciones de particulares, es decir de las presuntas víctimas, constituyen el mecanismo más innovador dado para garantizar el cumpli-

se estableció un sistema mínimo de tratamiento que consistía en la confección de listas de quejas de carácter reservado.

70 Esta lista tendría carácter confidencial y se comunicaría "a puerta cerrada".

71 Que afectaban a la población civil de los territorios ocupados por Israel.

72 Resolución 1503 (XLVIII) del Ecosoc del 27 de mayo de 1970.

73 Garretón, Roberto, op. cit., nota 69, p. 174.

74 Resolución 1235 (XLII) del Ecosoc del 6 de junio de 1967.

75 Salvo el Grupo de Trabajo sobre la Detención Arbitraria, toda vez que su mandato está referido a investigar casos de privaciones de la libertad impuestas arbitrariamente o que sean contrarias a la Declaración Universal de Derechos Humanos. Se ha calificado su mandato como un "hábeas corpus internacional". Cfr. Garretón, Roberto, op. cit., nota 69, p. 179.

76 Cfr. ibidem, pp. 176 y ss. 
miento del régimen protector de los tratados de derechos humanos. Aunque, cuando mucho, "los cinco instrumentos que contemplan este mecanismo de control lo hacen con carácter facultativo". ${ }^{77}$ Analizaremos a continuación las particularidades de los instrumentos del sistema de la ONU que incorporan las comunicaciones individuales, en tanto manifestación de la dimensión activa de la subjetividad jurídica internacional del individuo.

El Protocolo Facultativo I del Pacto Internacional de Derechos Civiles y Políticos (PIDCP) ${ }^{78}$ permite que los individuos que alegan haber sido víctimas de alguna violación de los derechos recogidos en el PIDCP, documenten las comunicaciones o quejas individuales ante el Comité de Derechos Humanos. ${ }^{79}$ Respecto a la competencia ratione personae se exige que el demandante sea la propia víctima de la violación (persona física) o su representante legalmente acreditado, por lo que no está permitida la actio popularis.

De manera excepcional se podrá presentar una comunicación en nombre de la víctima cuando "sea evidente que ésta no está en condiciones de presentar personalmente la comunicación". ${ }^{80}$ La víctima tiene que ser exclusivamente una persona física. En tal sentido, el Comité de Derechos Humanos desestimará cualquier queja proveniente de personas jurídicas que aleguen haber sido afectadas en alguno de los derechos recogidos en el PIDCP. Una vez aprobada la admisibilidad ${ }^{81}$ se pasa a la segunda fase de los procedimientos, en la cual se valoran los méritos de la comunicación. ${ }^{82}$ Es importante enfatizar que, en la opinión sobre el

77 Remiro Brotóns, Antonio, op. cit., nota 50, p. 1034.

78 PIDCP del 16 de diciembre de 1966. Protocolo Facultativo I del PIDCP del 16 de diciembre de 1996.

79 El Comité se ha hecho cargo de un número cada vez más grande de comunicaciones individuales, desde la entrada en vigor del Protocolo (1976). Una vez que el Comité recibe una queja individual, debe previamente establecer su competencia.

80 Reglamento del Comité de Derechos Humanos, artículo 90, inciso b). Asimismo, el abogado que ejerza la representación debe probar que cuenta con la autorización de la víctima (o de su familia inmediata), o que hubo circunstancias que le impidieron recibir tal autorización, o por la existencia de una relación anterior se presuma la representación.

81 La víctima, entre otros aspectos, debe haber probado el agotamiento de las vías ordinarias.

82 El Comité de Derechos Humanos presenta el material a la atención del Estado involucrado, el cual dispone de seis meses, periodo en el que debe responder a las imputaciones. Luego, las comunicaciones escritas del Estado parte involucrado y la demanda in- 
fondo, el Comité considera todas las informaciones escritas que hayan sido proporcionadas tanto por el individuo como por el Estado interesado. 83

Este procedimiento ha sido calificado de "cuasicontencioso", en tanto adopta la forma de un proceso judicial y la opinión final adquiere la formalidad de una sentencia. No obstante, jurídicamente no se encuentra en esta categoría, ya que no cuenta "con la fuerza jurídica sancionadora que una sentencia de un tribunal nacional tiene en el ámbito del derecho interno". ${ }^{84} \mathrm{La}$ opinión final del Comité constituye una recomendación, que implica para el Estado una obligación de medios antes que de resultados. ${ }^{85}$ Lo señalado en este parágrafo también es aplicable para los otros Comités.

En los últimos años, el número de comunicaciones individuales admisibles se ha incrementado de manera significativa, generándose un interesante sistema de precedentes para la interpretación y aplicación del PIDCP y del Protocolo. El Comité, adicionalmente, ha fortalecido la eficacia del mecanismo establecido en el Protocolo, en tanto, puede proponer medidas interinas para evitar daños irreparables a la presunta víctima. ${ }^{86}$

dividual son analizadas por el Comité y los resultados de su investigación comunicados a las partes. Finalmente, en el informe anual que presenta el Comité a la Asamblea General de la ONU se publica un sumario de los resultados.

83 El Comité, en cumplimiento de sus fines, garantiza el principio de igualdad de armas en la distribución de la carga de la prueba. Ésto significa que si el Estado no contradice los alegatos de la presunta víctima, el Comité los tomará en cuenta al momento de emitir su opinión.

84 Villán Durán, Carlos, Curso de Derecho Internacional de los Derechos Humanos, Madrid, Trotta, 2002, p. 198. Cfr. también Batalla, Ana, "La jurisprudencia del Comité de Derechos Humanos de Naciones Unidas y su impacto en los sistemas judiciales nacionales y regionales", Ius Inter Gentes, Revista de Derecho Internacional, año 2, núm. 3, 2005, pp. 30-34.

85 Dicha obligación de medios consistiría en realizar los mejores esfuerzos para seguir las recomendaciones del Comité de Derechos Humanos, y de los otros comités, con base en el principio de buena fe.

86 También el Comité obliga a los Estados partes a que especifiquen en sus informes periódicos las medidas adoptadas en la ejecución de las recomendaciones del Comité sobre los casos que fueron encontrados fundados. Cfr. Buergenthal, Thomas, Derechos humanos internacionales, México, Gernika, 1996, p. 72. 
En lo concerniente a la Convención para la Eliminación de la Discriminación Racial, ${ }^{87}$ se prevé que el mecanismo de procuración de la Convención esté formado por un Comité ${ }^{88}$ que está facultado para manejar las comunicaciones interestatales e individuales. ${ }^{89} \mathrm{El}$ sistema de recursos individuales es optativo, y requiere por ello de una declaración ad hoc por separado, donde se reconozca que el Comité tenga jurisdicción para recibir comunicaciones de esta índole..$^{90}$ Este Comité se encarga de las comunicaciones individuales sin ningún tipo de colaboración de alguna comisión de conciliación ad hoc. ${ }^{91}$

En relación a la Convención contra la Tortura, ${ }^{92}$ las medidas de instrumentación son administradas por el Comité contra la Tortura. Tales medidas abarcan un sistema obligatorio de informes así como mecanismos de demandas interestatales e individuales..$^{93}$ Todo Estado parte podrá, a través de una declaración, reconocer la competencia del Comité para recibir y examinar las comunicaciones enviadas por personas sometidas a su jurisdicción, o en su nombre, que aleguen ser víctimas de una violación de las normas de la Convención por un Estado parte. ${ }^{94}$ Entre otras disposiciones, se establece que este Comité examinará las comunicacio-

87 Convención Internacional sobre la Eliminación de todas las Formas de Discriminación Racial del 21 de diciembre de 1965.

88 Nos referimos al Comité para la Supresión de la Discriminación Racial. Véase Convención Internacional sobre la Eliminación de todas las Formas de Discriminación Racial, artículo 80.

89 Convención Internacional sobre la Eliminación de todas las Formas de Discriminación, artículo 14.

90 Convención Internacional sobre la Eliminación de todas las Formas de Discriminación Racial, artículo 14.

91 Luego de analizar la información recibida del Estado y el individuo involucrados, proporciona un resumen de sus conclusiones y elabora las recomendaciones pertinentes, las cuales publica en su informe anual a la Asamblea General de la ONU. Pese a que la Convención entró en vigor en 1969, sólo a partir de 1982 se alcanzó el número de diez Estados, necesario para la entrada en vigencia del sistema de comunicaciones individuales. Hasta la actualidad no ha sido muy significativo el número de recursos individuales tratados por el Comité. Buergenthal, Thomas, op. cit., nota 86, pp. 83 y 84 .

92 Convención contra la Tortura y otros Tratos o Penas Crueles Inhumanos o Degradantes del 10 de diciembre de 1984.

93 Estos dos mecanismos se basan en los del PIDCP y su Protocolo facultativo I.

94 Convención contra la Tortura y otros Tratos o Penas Crueles Inhumanos o Degradantes, artículo 22. 
nes recibidas, a la luz de toda la información proporcionada por la presunta víctima (o su representante) y por el Estado parte interesado.

En siguiente lugar, tenemos a la Convención sobre la Eliminación de todas las Formas de Discriminación contra la Mujer ${ }^{95}$ y su Protocolo Facultativo. ${ }^{96}$ En este último, se establece que todo Estado parte del Protocolo reconoce la competencia del Comité respectivo, para recibir y considerar las comunicaciones individuales. Dichas comunicaciones pueden ser presentadas por personas o grupos de personas que estén bajo la jurisdicción del Estado parte, y que aleguen haber sufrido por ese Estado parte alguna violación de los derechos enunciados en la Convención. ${ }^{97}$

Asimismo, tenemos a la Convención sobre la Protección de los Derechos de todos los Trabajadores Migratorios y de sus Familiares ${ }^{98}$ que crea el Comité del mismo nombre. Se estableció entre sus mecanismos, la cláusula especial para admitir comunicaciones individuales. ${ }^{99}$ Finalmente, la reciente Convención Internacional para la Protección de todas las Personas contra las Desapariciones Forzadas ${ }^{100}$ contiene también la citada cláusula especial para admitir comunicaciones individuales. ${ }^{101}$

\section{B. Sistemas regionales de protección de los derechos humanos}

En el sistema europeo de derechos humanos, el primer hito lo constituyó el Convenio Europeo de Derechos Humanos (CEDH). ${ }^{102}$ Este ins-

95 Convención sobre la Eliminación de todas las Formas de Discriminación contra la Mujer del 18 de diciembre de 1979.

96 Protocolo Facultativo de la Convención sobre la Eliminación de todas las Formas de Discriminación contra la Mujer del 6 de octubre de 1999.

97 Asimismo, se precisa que cuando se presente una comunicación en representación de personas o grupos de personas, se exigirá su consentimiento; salvo que el peticionario pueda justificar el actuar en su nombre sin tal consentimiento, artículo 2 del Protocolo Facultativo.

98 Convención Internacional sobre la Protección de los Derechos de todos los Trabajadores Migratorios y de sus Familiares del 18 de diciembre de 1990. Recién entró en vigor el 1o. de julio de 2003.

99 Convención Internacional sobre la Protección de los Derechos de Todos los Trabajadores Migratorios y de sus Familiares, artículo 77.

100 Convención Internacional para la Protección de todas las Personas contra las Desapariciones Forzadas del 23 de septiembre de 2005.

101 Convención Internacional para la Protección de todas las Personas contra las Desapariciones Forzadas del 23 de septiembre de 2005, artículo 31.

102 Convenio Europeo para la protección de los Derechos Humanos y de las Libertades Fundamentales del 4 de noviembre de 1950. Enmendado por los Protocolos Adicio- 
trumento internacional ${ }^{103}$ permitió al individuo presentar a la Comisión Europea de Derechos Humanos reclamaciones contra Estados partes del CEDH que hubieran aceptado la competencia facultativa de dicho órgano. En tal sentido, de considerarse admisible, la Comisión buscaba la obtención de una solución amistosa, y en el supuesto de fracasar podía ser sometido el caso al Tribunal Europeo de Derechos Humanos (TEDH) para una solución judicial.

Antes de la entrada en vigor del Protocolo núm. 11 al CEDH, los dos órganos originales de supervisión del CEDH resaltaron la importancia del derecho de la petición, pese a ser una cláusula facultativa del CEDH. El TEDH ${ }^{104}$ y la Comisión Europea reconocieron el derecho de naturaleza procesal que otorga el $\mathrm{CEDH}^{105}$ a los demandantes en virtud del cual éstos podían recurrir libremente a la antigua Comisión, sin que el Estado parte demandado impidiese o hiciese difícil su iniciativa. De igual manera, el TEDH en su momento evaluó las condiciones que rigen las peticiones individuales, y señaló que "no coinciden con los criterios nacionales relativos al locus standi, que pueden inclusive servir a propósitos distintos de los contemplados en el mencionado artículo 25". 106

El Protocolo núm. 9 al CEDH introdujo un valioso aporte al sistema, en tanto con anterioridad a él, el individuo, actor preponderante en un sistema de protección de derechos humanos, no contaba con plena subjetividad jurídica internacional. El Protocolo núm. 9 legitimó el acceso directo de los individuos al TEDH, aunque previo trámite ante la Comisión

nales números 3, 5, 8, 11 y 14; de mayo de 1963, 20 de enero de 1966, 19 de marzo de 1985, 28 de noviembre de 1996 y 13 de mayo de 2004, respectivamente.

103 CEDH, artículo 25 original.

104 TEDH, Caso Cruz Varas y otros v. Suecia. Application núm. 15576/89, sentencia del 20 de marzo de 1991, parágrafos. 92, 93 y 99. La Comisión Europea de DDHH, en su opinión del 7 de junio de 1990, fue más allá que el Tribunal, al señalar que Suecia violó la CEDH al impedir la eficacia del derecho de petición individual.

105 CEDH, artículo 25.1 original.

106 TEDH, Caso Norris v. Irlanda. Application núm. 10581/83, sentencia del 26 de octubre de 1998, p. 15, parágrafo 31. Debemos señalar que el artículo 76 del Reglamento de la Comisión Europea de DDHH establecía "que cuando se decidiera enviar un asunto al TEDH se comunicaría al individuo demandante y se le invitaría a presentar sus observaciones". En su primer caso Lawless $v$. Irlanda, aplicó la citada disposición reglamentaria. Cfr. TEDH, Caso Lawless v. Irlanda. Application núm. 332/57, sentencia del 14 de noviembre de 1960. Asimismo, con posterioridad el TEDH aceptó la presencia del abogado del demandante entre los agentes de la Comisión Europea. 
Europea. ${ }^{107}$ Entre los argumentos centrales que llevaron a este cambio, tenemos que: "se posibilitaría a los propios individuos decidir si se someterían o no sus casos a la Corte... se aseguraría el acceso de los individuos al tribunal internacional de los derechos humanos". ${ }^{108}$

Ello generó que se dé igual tratamiento a los individuos y al Estado, perfeccionándose la estructura del sistema, al asegurar la capacidad jurídico procesal de los individuos. Con este Protocolo se modifica el estatus del individuo en el sistema europeo de protección de derechos humanos, en tanto adquiere subjetividad jurídica internacional. De ese modo, además de un Estado parte y de la Comisión Europea, también el individuo peticionario podía someter un caso al conocimiento del TEDH.

El acceso de los individuos al TEDH se consolidó con la entrada en vigor del Protocolo núm. 11 al CEDH. ${ }^{109}$ Este Protocolo sustituyó a la Comisión y al TEDH por un nuevo Tribunal Permanente, con lo cual el sistema adquirió una naturaleza eminentemente judicial. El Protocolo núm. 11 incorpora el acceso directo o ius standi de los individuos al TEDH. Con este cambio, se consigue que los individuos puedan demandar al Estado sin la intervención de ningún órgano. En tal sentido, el individuo cuenta con legitimación activa ante el TEDH, de tal suerte que una vez agotados los recursos internos del Estado demandado, puede presentar la demanda directamente ante el TEDH. ${ }^{110}$

$\mathrm{Si}$ analizamos comparativamente el sistema europeo y el sistema interamericano de protección de derechos humanos, podemos apreciar que en lo referente al acceso individual los peticionarios tienen acceso directo al TEDH. Mientras que, a su vez, en el sistema interamericano los individuos no tienen tal acceso a la Corte Interamericana de Derechos $\mathrm{Hu}$ manos (Corte IDH), sino sólo a la Comisión Interamericana de Derechos

107 En los términos del artículo 3o. del mencionado Protocolo núm. 9.

108 Cançado, Antonio, op. cit., nota 11, p. 77; citando al Council of Europe, Protocol núm. 9 to the European Convention for the protection of Human Rights and Fundamental Freedoms-Explanatory Report, Strasbourg, CE, 1992, pp. 5-13. Los otros argumentos que se dieron eran: el desarrollo lógico del sistema de control de la CEDH; que se evitarían disparidades de tratamiento entre el Estado y el individuo; se perfeccionaría la estructura existente y se aseguraría así la igualdad de armas (equality of arms/égalité des arms).

109 Entró en vigor el 1o. de noviembre de 1998.

110 Carrillo Salcedo, Juan Antonio, El Convenio Europeo de Derechos Humanos, Madrid, Tecnos, 2002, pp. 54 y 55. Para un mayor detalle de la competencia ratione personae del TEDH, cfr. Amerasinghe, Félix, op. cit., nota 63, pp. 735-755. 
Humanos (CIDH); aunque a diferencia del sistema europeo sin la necesidad de ser víctima. En adición a lo afirmado, el Protocolo núm. 11 afirma el estatus del individuo como sujeto de derecho internacional pleno en el sistema europeo. Por su lado, en el sistema interamericano el individuo posee subjetividad jurídica internacional, en tanto goza del locus standi en todas las etapas del proceso, pero dicha subjetividad no es plena al no poseer ius standi.

Pese a las bondades de la Reforma, ésta no responde al contexto actual europeo, en el cual el número de demandas se ha incrementado de modo considerable, ${ }^{111}$ lo cual ha originado que aproximadamente un $90 \%$ de las demandas hayan sido declaradas inadmisibles. ${ }^{112}$ El procedimiento establecido se caracteriza por su complejidad, puesto que la evaluación del caso por la Gran Sala (órgano integrante del TEDH) depende de conceptos jurídicos indeterminados y vagos. ${ }^{113}$ Frente a esta problemática, fue abierto a la firma el Protocolo núm. 14. ${ }^{114}$ Este nuevo Protocolo establece mecanismos para filtrar las demandas individuales, y su adopción obedece al propósito de reforzar y mantener la eficacia del sistema de control de la CEDH.

En el sistema interamericano, nos concentraremos en el análisis del Reglamento actual de la Corte IDH, en relación a la subjetividad jurídica internacional del individuo en su dimensión activa. ${ }^{115}$ No obstante, como aspecto preliminar debemos recordar que los individuos pueden presentar denuncias, ante la CIDH, por violación de derechos humanos en contra de un Estado miembro de la Organización de Estados Americanos (OEA), no siendo necesario que el peticionario sea la víctima, a diferen-

$111 C f r$. Mahoney, Paul, "Speculating on the future of the reformed European Court of Human Rights", Human Rights Law Journal, vol. 20, 1999, pp. 1-4. Este trabajo algo temprano ya alertaba sobre los aspectos problemáticos de la reforma.

112 Pastor Ridruejo, José Antonio, "El Tribunal Europeo de Derechos Humanos: la reforma de la reforma", en varios autores, Sistemas internacionales de protección de los derechos humanos en el umbral del siglo XXI, San José, IIDH, 2003, pp. 673-675.

113 Adicionalmente, el procedimiento es extenso al poder generar que un caso llegue a ser objeto de hasta cuatro exámenes sucesivos. Cfr. Ibidem, p. 674.

114 Fue abierto a la firma el 13 de mayo de 2004.

115 Para un mayor detalle de la competencia ratione personae de la Corte IDH y de la CIDH. Cfr. Faúndez, Héctor, El Sistema Interamericano de Protección de los Derechos Humanos. Aspectos institucionales y procesales, 3a. ed., San José, Instituto Interamericano de Derechos Humanos, 2004, pp. 605-618 y pp. 240-257, respectivamente. 
cia del sistema europeo. ${ }^{116}$ Sin embargo, las decisiones de la CIDH, al ser recomendaciones, no constituyen sentencias, por lo que no implican obligaciones de resultado sino de medios, como ha señalado la Corte IDH en su jurisprudencia. ${ }^{117}$

Como apreciación general, se debe señalar que ninguno de los tres primeros reglamentos de la Corte IDH identificó quiénes eran las partes en el procedimiento ante la Corte IDH, limitándose a señalar que por la expresión "partes en el caso" se debía entender las partes en un caso ante la Corte IDH. El avance cualitativo más destacable del tercer Reglamento de la Corte IDH fue el otorgar a los representantes de las víctimas o de sus familiares la facultad de presentar, en forma autónoma, sus propios argumentos y pruebas en la etapa de reparaciones. La nueva norma ${ }^{118}$ le otorgó legitimidad activa, en la etapa de reparaciones, a los representantes de las víctimas o de sus familiares, quienes con el anterior Reglamento presentaban sus alegaciones a través de la CIDH, la cual las hacía suyas. Asimismo, la Corte IDH pasó a comunicar a los denunciantes

$116 \mathrm{CADH}$, artículo 41. La Comisión tiene la función principal de promover la observancia y la defensa de los derechos humanos, y en el ejercicio de su mandato tiene las siguientes funciones y atribuciones:... f. Actuar respecto de las peticiones y otras comunicaciones en ejercicio de su autoridad de conformidad con lo dispuesto en los artículos 44 al 51 de esta Convención... artículo 44. Cualquier persona o grupo de personas, o entidad no gubernamental legalmente reconocida en uno o más Estados miembros de la Organización, puede presentar a la Comisión peticiones que contengan denuncias o quejas de violación de esta Convención por un Estado parte. Cfr. también el artículo 23 del Reglamento de la Corte IDH. En torno al concepto de víctima, es importante señalar que de acuerdo a la jurisprudencia de la Corte IDH se incluye bajo determinadas circunstancias a los familiares. Cfr. Corte IDH, Caso Blake v. Guatemala, Sentencia del 24 de enero de 1998, serie C, núm. 36; Corte IDH, Caso de los "niños de la calle" (Villagrán Morales y otros) v. Guatemala, Sentencia del 19 de noviembre de 1999, serie C, núm. 63; Corte IDH, Caso Bámaca Velásquez v. Guatemala, Sentencia del 25 de noviembre de 2000, serie $\mathrm{C}$, núm. 70.

117 Corte IDH, Caso Loayza Tamayo v. Perú, Sentencia del 17 de septiembre de 1997, serie C, núm. 33, parágrafo 80: “en virtud del principio de buena fe, consagrado en el mismo artículo 31.1 de la Convención de Viena, si un Estado suscribe y ratifica un tratado internacional, especialmente si trata de derechos humanos, como es el caso de la Convención Americana, tiene la obligación de realizar sus mejores esfuerzos para aplicar las recomendaciones de un órgano de protección como la Comisión Interamericana que es, además, uno de los órganos principales de la Organización de los Estados Americanos, que tiene como función "promover la observancia y la defensa de los derechos humanos" en el hemisferio (Carta de la OEA, artículos 52 y 111)".

118 Véase el artículo 23 del Reglamento de la Corte IDH de 1996. 
originales, a las víctimas o a sus representantes y familiares, los principales actos del procedimiento escrito del caso que se ventilaba ante la Corte IDH y las sentencias respectivas. ${ }^{119}$

El nuevo y cuarto Reglamento de la Corte IDH, ${ }^{120}$ reconoce al individuo demandante, de modo indudable y por primera vez en la historia del sistema interamericano, como sujeto de derecho internacional de los derechos humanos con capacidad jurídico-procesal. De esa manera, se produce la participación plena locus standi de los individuos en todas las etapas del proceso ante la Corte IDH, de manera autónoma, con excepción de la presentación de la demanda. El individuo ha visto así fortalecida su capacidad procesal y su calidad de parte ante la Corte IDH y en general en este sistema regional, en tanto ya no es un simple observador de su propio proceso, sino que se constituye en parte procesal y material del mismo.

Como en su momento el juez Piza Escalante sostuvo en su voto disidente en el caso Velásquez Rodríguez $v$. Honduras:

En el proceso ante ésta [Corte IDH], la única parte activa, en sentido sustancial, son la víctima o sus causahabientes, titulares de los derechos reclamados y acreedores de las prestaciones que en la sentencia se declaren... En cambio la Comisión, parte imparcial e instrumental, al modo de Ministerio Público del sistema interamericano de protección de los derechos humanos, lo es solamente en el sentido procesal, como actora en el juicio, nunca en el sustancial o material, como acreedora de la sentencia. ${ }^{121}$

El locus standi in judicio, recogido en el nuevo reglamento de la Corte IDH, se basa en que si se poseen derechos protegidos, entonces se

119 Véase los artículos 23, 35, 37 y 57.6 del Reglamento de la Corte IDH de 1996.

120 Nos referimos en específico al artículo 23. El actual y cuarto Reglamento de la Corte IDH fue aprobado el 24 de noviembre de 2000 y entró en vigor el 1o. de junio de 2001. Este reglamento ha sido reformado parcialmente por la Corte IDH en su LXI periodo ordinario de sesiones, celebrado del 20 de noviembre al 4 de diciembre de 2003. Dicha modificación se encuentra en vigor desde el 1o. de enero de 2004.

121 Corte IDH, Caso Velásquez Rodríguez $v$. Honduras, Sentencia del 29 de julio de 1988, serie C, núm. 4, voto disidente del juez Piza Escalante, parágrafo 3. No obstante, como señala Faúndez, desde el punto de vista formal, las únicas partes en el procedimiento ante la Corte IDH son la CIDH y los Estados que, ya sean como demandantes o demandados, participan en el mismo. En opinión del mismo autor, existe un amplio consenso en cuanto a que el individuo no es parte en el procedimiento ante la Corte IDH. Cfr. Faúndez, Héctor, op. cit., nota 115, p. 616. 
debe contar con la capacidad procesal de ejercerlos. ${ }^{122}$ Se entiende así que sin el locus standi in judicio de ambas partes, cualquier sistema de protección de derechos humanos se encuentra considerablemente mitigado, toda vez que no es razonable concebir derechos sin la capacidad de ejercerlos directamente. En tal sentido, el entonces juez de la Corte IDH, Cançado Trindade sostuvo que:

El espectro de la persistente denegación de la capacidad procesal del individuo peticionario ante la Corte Interamericana, verdadera capitis diminutio, emanó de consideraciones dogmáticas propias de otra época histórica tendentes a evitar su acceso directo a la instancia judicial internacional, consideraciones éstas que, en nuestros días... carecen de sustentación o sentido, aún más tratándose de un tribunal internacional de derechos humanos. ${ }^{123}$

En el mismo Reglamento, ${ }^{124}$ adicionalmente se señala que el término partes en el caso involucra a la presunta víctima, al Estado aludido y, de manera únicamente procesal, a la CIDH. Esta modificación se ha plasmado en la jurisprudencia de la Corte IDH. ${ }^{125}$ Ésto significa que, en el pro-

122 Cfr. Corte IDH. Caso Castillo Páez v. Perú. Excepciones Preliminares, Sentencia del 30 de enero de 1996, serie C, núm. 24, voto razonado del juez Cançado Trindade, parágrafo 14; Corte IDH. Caso Loayza Tamayo v. Perú. Excepciones Preliminares, Sentencia del 31 de enero de 1996, serie C, núm. 25, voto razonado del juez Cançado Trindade, parágrafo 14 .

123 Corte IDH. Caso Castillo Páez v. Perú. Excepciones Preliminares, Sentencia del 30 de enero de 1996, serie C, núm. 24, voto razonado del juez Cançado Trindade, parágrafo 16. En este sentido, se ha propuesto, de lege ferenda, superar gradualmente la concepción paternalista y anacrónica de la total intermediación de la CIDH entre el individuo y la Corte IDH, según criterios y reglas claras, precisas y cuidadosamente definidas. $C f r$. al respecto el parágrafo 17 de los votos razonados reseñados.

124 Reglamento de la Corte IDH, artículo 23. Participación de las presuntas víctimas. 1. Después de admitida la demanda, las presuntas víctimas, sus familiares o sus representantes debidamente acreditados podrán presentar sus solicitudes, argumentos y pruebas en forma autónoma durante todo el proceso. 2. De existir pluralidad de presuntas víctimas, familiares o representantes debidamente acreditados, deberán designar un interviniente común que será el único autorizado para la presentación de solicitudes, argumentos y pruebas en el curso del proceso, incluidas las audiencias públicas. 3. En caso de eventual desacuerdo, la Corte resolverá lo conducente.

125 Corte IDH, Caso "cinco pensionistas" v. Perú, Sentencia del 28 de febrero de 2003, serie C, núm. 98; y Corte IDH, Caso de los hermanos Gómez Paquiyauri v. Perú, Sentencia del 8 de julio de 2004, serie C, núm. 110. 
cedimiento ante la Corte IDH, se constituyen tres posiciones distintas. Así tenemos a la presunta víctima (o sus familiares o representantes legales), con subjetividad en el derecho internacional; la de la CIDH, como órgano de supervisión de la Convención Americana sobre Derechos Humanos (CADH) y auxiliar de la Corte IDH; y la del Estado demandado. Todo este cambio permitió situar a los distintos actores en su real ubicación, y como afirma Cançado se contribuyó a:

Una mejor instrucción del proceso; a asegurar el principio del contradictorio, esencial en la búsqueda de la verdad y la prevalencia de la justicia bajo la Convención Americana; a reconocer el ser de la esencia del contencioso administrativo internacional de los derechos humanos consistente en la contraposición directa entre los individuos demandantes y los Estados demandados; a reconocer el derecho de libre expresión de las propias presuntas víctimas, el cual es un imperativo de equidad y transparencia del proceso; y, last but no least, a garantizar la igualdad procesal de las partes (equality of arms / égalité des armes) en todo el procedimiento ante la Corte. ${ }^{126}$

Con el nuevo Reglamento, las presuntas víctimas, sus familiares o representantes pueden presentar solicitudes, argumentos y pruebas autónomas durante todo el proceso. ${ }^{127}$ Además, durante las audiencias públicas, pueden los peticionarios hacer uso de la palabra para la presentación de sus argumentos y pruebas, lo cual se condice con su condición de verdadera parte en el proceso, tal y como es reconocida en el Reglamento de la Corte IDH. ${ }^{128}$ Como corolario, las presuntas víctimas, sus familiares o representantes legales, en todas las fases del proceso, pasan a disfrutar de todas las obligaciones y facultades, en materia procesal, las que hasta el

126 Cançado, Antonio, op. cit., nota 11, pp. 182 y 183.

127 Reglamento de la Corte IDH, artículo 23.1.

128 Reglamento de la Corte IDH, artículo 2. 23. "la expresión "partes en el caso" significa la víctima o la presunta víctima, el Estado y, sólo procesalmente, la Comisión". Se debe precisar que ya, en la reunión anual Corte IDH-CIDH, celebrada el 12 de octubre de 1998, en cumplimiento de las resoluciones de la Asamblea General de al OEA AG/RES.1041 (XX-/90) y Resolución AG/RES.1330 (XXXV-/95) se dispuso dar preeminencia al papel de la víctima ante la $\mathrm{CDH}$, y se acordó que se estudiaría la posibilidad de implementar una eventual reforma a su Reglamento, para que los peticionarios puedan presentar escritos autónomos en todas las etapas del proceso ante la Corte IDH y no sólo en la etapa de reparaciones. 
reglamento pasado, eran privativos sólo de la CIDH y del Estado (salvo en la fase de reparaciones).

La Asamblea General de la OEA contribuyó con estas modificaciones, al recomendar a la Corte IDH que permitiese "la participación directa de la víctima, en calidad de parte, a partir del momento que el caso es sometido a su competencia". ${ }^{129}$ El nuevo Reglamento impide que en un proceso ante la Corte IDH se imposibilite a las víctimas o a los peticionarios hacer valer sus derechos, producida por la diversidad de criterios de los representantes de las víctimas o de peticionarios con la estrategia de la CIDH, evitándose la indefensión. ${ }^{130}$

Se debe señalar que la participación directa de los individuos no se ha limitado a los casos contenciosos y opiniones consultivas, sino que también ha abarcado las medidas provisionales de protección. ${ }^{131}$ La jurisprudencia de la Corte IDH ha fortalecido en este ámbito la posición de los individuos en la búsqueda de protección. En los casos del Tribunal Constitucional ${ }^{132}$ y Loayza Tamayo, ${ }^{133}$ las víctimas sometieron directamente a la Corte IDH solicitudes de medidas provisionales. La Corte IDH, en pleno, ratificó las referidas medidas adoptadas por su presidente. Estos episodios demuestran la importancia del acceso directo de los individuos a la Corte IDH, especialmente en una situación de extrema gravedad y urgencia. ${ }^{134}$

129 AG/RES. 1701 (XXX-O/00), 5 de junio de 2000, parágrafo 7.

130 Cfr. Salvioli, Fabián, "El sistema interamericano de protección de los derechos humanos", Dossier Documentaire, Strasbourg, Institut International de Droit de l'Homme, vol. 1, 34 ème Session d'enseignement, 2003, p. 449.

$131 \mathrm{CADH}$, artículo 63.2. En casos de extrema gravedad y urgencia, y cuando se haga necesario evitar daños irreparables a las personas, la Corte, en los asuntos que esté conociendo, podrá tomar las medidas provisionales que considere pertinentes. Si se tratare de asuntos que aún no estén sometidos a su conocimiento, podrá actuar a solicitud de la Comisión. Cfr. Faúndez, Héctor, op. cit., nota 115, pp. 509-590.

132 Corte IDH, Caso del Tribunal Constitucional $v$. Perú, Resolución sobre medidas provisionales del 14 de agosto de 2000.

133 Corte IDH, Caso Loayza Tamayo v. Perú, Resolución sobre medidas provisionales del 3 de febrero de 2001.

134 Asimismo, con la finalidad de dar la mayor participación autónoma a las presuntas víctimas y a sus representantes, en el procedimiento ante la Corte IDH se ha emitido la Resolución General sobre Medidas Provisionales de Protección. Por esta Resolución, la Corte IDH permite, respecto a los casos bajo su conocimiento, que las presuntas víctimas (sus familiares, o sus representantes legales) presenten de manera directa y autónoma las solicitudes de dichas medidas, y que participen en su procedimiento respectivo. 
Es preciso remarcar que, pese a la amplia legitimación procesal del individuo, dicha legitimación es imperfecta en tanto no le confiere una acción directa o ius standi ante la Corte IDH, vale decir la capacidad autónoma y sin intermediarios de plantear de manera directa demandas. En esta línea, si bien el actual Reglamento presenta importantes innovaciones, se necesita la creación de un mecanismo más sólido con el fin de consagrar un ius standi. ${ }^{135}$

Como propuestas de futuros cambios, con el fin de pasar del locus standi al ius standi ante la Corte IDH, está la necesidad del individuo de poder acceder directamente a la Corte IDH. ${ }^{136} \mathrm{El}$ acceso directo señalado implicaría una enmienda a la $\mathrm{CADH}^{137}$ con el objetivo de tornar la jurisdicción de la Corte IDH automáticamente obligatoria para todos los Estados partes de la CADH. ${ }^{138} \mathrm{La} \mathrm{CIDH}$, en este supuesto, retendría funciones distintas a la contenciosa. ${ }^{139}$

Por otro lado, la incorporación del ius standi en el sistema interamericano probablemente afronte ciertas limitaciones. Una limitación fáctica, en tanto el acceso amplio del que gozan los peticionarios para acceder al sistema interamericano (a través de la CIDH), se restringiría al poder acceder directamente al órgano jurisdiccional. Igualmente, se daría una limitación jurídica, que podría generar que el concepto de víctima adquiera una dimensión muy significativa, en tanto se erigiría como una condición necesaria para acceder al proceso ante la Corte IDH.

135 Cfr. Ciurlizza, Javier y Carol, Bellido, "Del locus standi al ius standi del individuo en el sistema interamericano de protección de derechos humanos", Ius Inter Gentes, Revista de Derecho Internacional, año 2, núm. 2, 2005, p. 13.

136 En este contexto, se entiende a la Corte IDH como único órgano jurisdiccional, dotada de una posible primera instancia con el fin de considerar la admisibilidad de las peticiones; lo cual no se contrapone con el mantenimiento de las funciones no-contenciosas de la CIDH.

137 En concreto se tendría que hacer una enmienda al artículo 62 de la CADH que señala: "1. Todo Estado parte puede, en el momento del depósito de su instrumento de ratificación o adhesión de esta Convención, o en cualquier momento posterior, declarar que reconoce la competencia de la Corte sobre todos los casos relativos a la interpretación. 2. La declaración puede ser hecha incondicionalmente, o bajo condición de reciprocidad, por un plazo determinado o para casos específicos".

138 Por lo tanto, no se necesitaría una manifestación adicional de consentimiento posterior a la ratificación de la CADH.

139 Como, por ejemplo, la realización de misiones de observación in loco y la elaboración de informes. 
En el sistema africano, la Carta Africana ${ }^{140}$ no contempla expresamente la actuación de los particulares. No obstante, la situación ha cambiado con la adopción de su Protocolo, ${ }^{141}$ que ha introducido un nuevo órgano de control el cual es el Tribunal Africano de Derechos Humanos y de los Pueblos. Respecto a la cuestión de las denuncias individuales, el Protocolo contempla la posibilidad de que los particulares las presenten aunque con previa aceptación de la jurisdicción del Tribunal por el Estado en cuestión. Sin embargo y a diferencia de otros tratados internacionales sobre derechos humanos, el Protocolo configura la técnica de las denuncias individuales como una facultad que el Tribunal puede conferir. ${ }^{142}$

Finalmente debemos referirnos a la Comisión Permanente Árabe de Derechos Humanos, ${ }^{143}$ la cual cuenta con competencia para fomentar los derechos humanos, desarrollar una concepción común entre los Estados

140 Carta Africana de los Derechos Humanos y de los Pueblos del 27 de julio de 1981. También conocida como Carta de Banjul, cuya entrada en vigor fue el 21 de octubre de 1986. El mecanismo de demandas individuales de la Carta Africana es muy similar al procedimiento establecido por la Resolución 1503 de Ecosoc, siendo bastante disímil del sistema de peticiones individuales de otros sistemas regionales. Cfr. Buerguenthal, Thomas, op. cit., nota 86, p. 257.

141 Protocolo a la Carta Africana de los Derechos del Hombre y de los Pueblos del 10 de junio de 1998, artículo 5. Acceso a la Corte... 3. El Tribunal puede permitir a los individuos y a las organizaciones no gubernamentales (ONG) dotadas de estatuto de observador ante la Comisión la introducción, directamente ante el Tribunal, de denuncias de conformidad con el artículo 34 (6) de este Protocolo. Pero existe otro posible filtro previo, el que se deriva del artículo 6.1 del Protocolo, de conformidad con el cual: "El Tribunal, antes de estatuir sobre la admisibilidad de una denuncia introducida en aplicación del artículo 5(3) del presente Protocolo, puede solicitar la opinión de la Comisión, que debe darla lo antes posible". El artículo 34.6 del Protocolo señala que: "En cualquier momento desde la ratificación del presente Protocolo, el Estado deberá declarar que acepta la competencia de la Corte para recibir las demandas enunciadas en el artículo 5(3) del presente Protocolo. La Corte no recibirá ninguna demanda del artículo 5(3) concerniente a un Estado parte que no haya realizado tal declaración".

142 Para mayores detalles sobre el sistema africano de protección de derechos humanos se recomienda la lectura de Fischel de Andrade, José, "El sistema africano de protección de los derechos humanos", Revista del Instituto Interamericano de Derechos Humanos, t. VI, 1999, pp. 449-492; Udombana, Nsongurua, "Can the Leopard Change Its Sopts? The African Union Treaty and Human Rights", American University International Law Review, vol. 17, núm. 6, 2002, pp. 1177-1257 y Fernández de Casadevante, Carlos, Derecho internacional de los derechos humanos, 2a. ed., Madrid, DILES, 2003, pp. 243-251.

143 Creada por la Liga de Estados Árabes, esta Comisión está integrada por representantes de cada uno de los Estados miembros. 
miembros sobre derechos humanos y formular recomendaciones al Consejo de la Liga de Estados Árabes. ${ }^{144}$

\section{La situación de las víctimas ante la Corte Penal Internacional}

Como consideración preliminar debemos señalar que el ámbito del derecho penal internacional, una de cuyas manifestaciones de institucionalización es precisamente la Corte Penal Internacional (CPI), es el campo en el cual toma lugar la otra dimensión de la subjetividad jurídica internacional individual, es decir, la dimensión pasiva. Pese a no ser objeto de análisis del presente trabajo tal dimensión, creemos pertinente hacer una referencia general en los siguientes parágrafos.

En el derecho internacional contemporáneo existen normas que directamente imponen obligaciones a los individuos, y que involucran intereses vitales de la comunidad internacional en su totalidad. Tales reglas se generaron en un primer momento en el ámbito del derecho internacional humanitario, a través de la imposición de responsabilidad internacional penal individual por las violaciones serias de las leyes y usos de la guerra. Con posterioridad se ha atribuido responsabilidad internacional individual por crímenes de derecho internacional, independientemente de su conexión con un conflicto armado, siendo el caso de los crímenes de genocidio y de lesa humanidad. De esa manera, la dimensión pasiva de la subjetividad jurídica internacional implica, como apunta Cassese, que los individuos están:

At present under many international obligations, some solely relating to armed conflict, others (those on crimes against humanity, genocide, aggression, terrorism, torture) also concerning peacetime. These obligations are incumbent upon all individuals of the world; they are all obliged to refrain from breaching the aforementioned rules, if they do not do so, they are accountable for their, transgression. ${ }^{145}$

144 El 15 de septiembre de 1994, la Liga adoptó la Carta Árabe de Derechos Humanos y el Consejo Islámico adoptó la Declaración Islámica Universal de los Derechos del Hombre en 1981. Para más detalles, cfr. Mayer, Ann, Islam and Human Rights: Tradition and Politics, Oxford, Westview Press, 1999.

145 Cassese, Antonio, op. cit., nota 1, pp. 144 y 145. 
De lo anterior, se genera que los individuos puedan ser procesados y sancionados ante cortes nacionales de cualquier Estado como consecuencia de su responsabilidad internacional individual o también lo sean ante una jurisdicción penal internacional con competencia sobre los crímenes respectivos. De igual forma se deriva que la generación y sanción de responsabilidad internacional individual puede ser realizada ya sea que el individuo actúe como agente (de iure o de facto) del Estado o a título particular.

Ahora bien, los estatutos de los tribunales militares internacionales de Nüremberg y Tokio establecidos para juzgar penalmente a los más serios responsables de los crímenes de lesa humanidad, de guerra y agresión acaecidos en la Segunda Guerra Mundial, no contuvieron disposición alguna sobre la participación de las víctimas en los respectivos procesos penales internacionales. ${ }^{146}$ En el caso de los tribunales penales internacionales ad hoc para la ex Yugoslavia y Ruanda, cuya competencia ratione materiae está constituida por violaciones graves del derecho internacional humanitario, crímenes de lesa humanidad y genocidio ${ }^{147}$ sólo se hace una referencia muy general a la restitución de propiedad en el Estatuto del Tribunal para la ex Yugoslavia y los Reglamentos de Procedimiento y Prueba de ambos tribunales, ${ }^{148}$ siendo que hasta la fecha las cámaras de juicio de los Tribunales no han emitido pronunciamiento alguno sobre el particular. ${ }^{149}$ Por su parte, a nivel de los llamados tribuna-

$146 C f r$. Estatuto del Tribunal Penal Internacional de Nüremberg, artículo 6o., y Estatuto del Tribunal Penal Internacional para el Lejano Oriente, artículo 5, http://www.yale. edu/lawweb/avalon/imt/imt.htm.

147 Estatuto del Tribunal Penal Internacional para la ex Yugoslavia. U. N. Doc. S/RES/827 (25 de mayo, 1993), artículo 2o. (infracciones graves a los Convenios de Ginebra de 1949), artículo 3o. (violaciones de las leyes o prácticas de guerra), artículo 4o. (genocidio) y artículo 5o. (crímenes contra la humanidad). Estatuto del Tribunal Penal Internacional para Ruanda. U. N. Doc. S/RES/955 (8 de noviembre, 1994), artículo 20. (genocidio), artículo 3o. (crímenes contra la humanidad) y artículo 4o. (violaciones del artículo 3o. común a los Convenios de Ginebra y al Protocolo adicional II).

148 Estatuto del Tribunal Penal Internacional para la ex Yugoslavia, artículo 24.3; Reglas de Procedimiento y Prueba de los Tribunales Penales Internacionales para la ex Yugoslavia y Ruanda, artículo 105.

149 En todo caso, lo anterior tiene como condición la existencia de los respectivos procedimientos nacionales. Sobre el particular, es oportuno mencionar, como refiere Bassiouni, que las cortes domésticas estuvieron mal preparadas para ver estos casos. Bassiouni, M. Cherif, “International Recognition of Victims' Rights", Human Rights Law Review, vol. 6, núm. 2, 2006, p. 243. 
les penales mixtos podemos señalar que, por ejemplo, la Corte Especial para Sierra Leona sigue el mismo esquema de los tribunales ad hoc. ${ }^{150}$

Resulta claro que no se prestó atención a los intereses de las víctimas en el marco de los tribunales penales internacionales referidos. Este aspecto ha cambiado con el establecimiento de la CPI, la cual tiene competencia ratione materiae sobre los crímenes de agresión, genocidio, lesa humanidad y guerra. ${ }^{151}$

Es oportuno, en este punto, recodar que no son individuos particulares los que pueden activar un proceso ante la CPI (falta de ius standi). En este contexto, tenemos que existen importantes razones que explican tal falta de legitimación activa del individuo ante la CPI. Entre las principales se pueden señalar: a) El temor de los Estados a que la CPI se viera desbordada con un incesante número de quejas individuales; b) Aunque en menor grado que los tribunales penales internacionales para la ex $\mathrm{Yu}$ goslavia y Ruanda, la CPI tiene una importante influencia del proceso inquisitorio propio del common law; c) Debido a que el Estatuto de la CPI está claramente ubicado dentro del derecho penal internacional, se busca esencialmente proteger a la población, es decir, la persona humana como bien jurídico, y d) Que el principio de justicia del Estatuto de la CPI no equivale a la justicia reparatoria a las víctimas sino al orden público internacional. ${ }^{152}$ No obstante, tal situación ha sido criticada por cierto sector de la doctrina. ${ }^{153}$ Tal crítica se basa precisamente en la falta de ius

150 Estatuto de la Corte Especial de Sierra Leona, artículo 14; Reglas de procedimiento y prueba, regla 105, http://www.sc-sl.org/. Se debe precisar que, a diferencia de los tribunales ad hoc establecidos por Resoluciones del Consejo de Seguridad, los tribunales mixtos se establecieron por acuerdo entre la Asamblea General de Naciones Unidas y los Estados respectivos. Así tenemos los tribunales de Camboya, Kosovo, Sierra Leona y Timor Oriental.

151 Estatuto de la CPI. Aprobado por la Conferencia Diplomática de Roma del 17 de junio de 1998. A/CONF.183/9 y que entró en vigor el 1o. de julio de 2002. Cfr. artículo 5o. (crimen de agresión), artículo 6o. (genocidio), artículo 7o. (crímenes de lesa humanidad) y artículo 8o. (crímenes de guerra).

152 Cfr. García, Daniel, "La configuración jurídica de las víctimas de los crímenes de la competencia de la Corte Penal Internacional”, en Carrillo Salcedo, Juan Antonio (ed.), La criminalización de la barbarie: La Corte Penal Internacional, Madrid, Consejo General del Poder Judicial, 2000, pp. 457-479.

153 Entre otros tenemos a idem. 
standi y en la aproximación excesivamente proteccionista del Estatuto de la CPI con respecto a las víctimas. ${ }^{154}$

No obstante, como señaláramos, la CPI entraña un cambio importante. Tal cambio reposa en el hecho que se supera el modelo adversarial process, propio del Common Law, el cual fue seguido por los tribunales penales internacionales precedentes; para incluir algunos elementos del proceso inquisitorial system del Civil Law, el cual hace factible, como recuerda Schabas, ${ }^{155}$ la participación de las víctimas en calidad de parte civil. Particularmente, coincidimos con Bassiouni ${ }^{156}$ cuando sostiene que las más destacables normas del Estatuto de la CPI, en lo concerniente a los derechos de las víctimas, son las relativas a la indemnización de las víctimas. El Estatuto de la CPI ha previsto el establecimiento de un Fondo Fiduciario para el beneficio de las víctimas y de sus familiares, siendo que los recursos del Fondo tienen como fuentes contribuciones voluntarias de los Estados partes y también sumas o bienes que la CPI reciba a título de multa o decomiso y que sean transferidos al Fondo. ${ }^{157}$

Además de lo anterior, como puntos positivos del Estatuto en la materia tenemos que los particulares pueden enviar información al fiscal, para que ex oficio sea él quien remita (a su discreción) un caso a la CPI. ${ }^{158}$ A su vez, las víctimas pueden intervenir en la fase de instrucción

154 Ibidem, pp. 471 y ss.

155 Schabas, William, Introduction to the International Criminal Court, 2a. ed., Cambridge, Cambridge University Press, 2004, p. 172.

156 Bassiouni, M, Cherif, op. cit., nota 149, p. 245.

157 Estatuto de la CPI, artículo 79. "Fondo Fiduciario. 1. Por decisión de la Asamblea de los Estados Partes se establecerá un fondo fiduciario en beneficio de las víctimas de crímenes de la competencia de la Corte y de sus familias. 2. La Corte podrá ordenar que las sumas y los bienes que reciba a título de multa o decomiso sean transferidos al Fondo Fiduciario. 3. El Fondo Fiduciario será administrado según los criterios que fije la Asamblea de los Estados Partes". Cfr. también las regulaciones del Fondo Fiduciario para las Víctimas. Resolución ICC-ASP/4/Res.3 adoptada en la cuarta reunión de la Asamblea de Estados Partes del Estatuto de la CPI del 3 de diciembre de 2005.

158 Estatuto de la CPI, artículo 15. "El fiscal. 1. El fiscal podrá iniciar de oficio una investigación sobre la base de información acerca de un crimen de la competencia de la Corte. 2. El fiscal analizará la veracidad de la información recibida. Con tal fin, podrá recabar más información de los Estados, los órganos de las Naciones Unidas, las organizaciones intergubernamentales $u$ otras fuentes fidedignas que se considere apropiadas y podrá recibir testimonios escritos u orales en la sede de la Corte. 3. El fiscal, si llegare a la conclusión de que existe fundamento suficiente para abrir una investigación suficiente 
y en el curso del proceso, así como tienen la posibilidad de solicitar a la CPI una decisión sobre las consecuencias civiles de la condena penal. ${ }^{159}$ En tal sentido, las víctimas además de las observaciones que pueden presentar a la Sala de Cuestiones Preliminares, ${ }^{160}$ y a la CPI en las actuaciones relativas a la competencia y admisibilidad, pueden tomar parte en el proceso que se sustente ante la CPI. ${ }^{161}$

Es oportuno tener en cuenta que el artículo 68.3 del Estatuto de la CPI define a las víctimas sobre la base de la afectación de sus intereses personales, ${ }^{162}$ mientras que el artículo $75^{163}$ viabiliza el derecho a la reparación. De manera más precisa, la regla 85.a de las Reglas de Procedi-

para una investigación presentará a la Sala de Cuestiones Preliminares una petición de autorización para ello, junto con la documentación justificativa que haya reunido".

159 Estatuto de la CPI, artículo 75. Reparación a las víctimas. Véase también Estatuto de la CPI, artículo 79. Fondo Fiduciario

160 Estatuto de la CPI, artículo 15. "3. Las víctimas podrán presentar observaciones a la Sala de Cuestiones Preliminares, de conformidad con las Reglas de Procedimiento y Prueba".

161 En términos generales los autores destacan en sentido positivo el tratamiento que el Estatuto confiere a las víctimas de los crímenes de la competencia de la CPI. Cfr. por ejemplo Cassese, Antonio, "The Statute of the International Criminal Court: some Preliminary Reflections", European Journal of International Law, vol. 10, núm. 1, 1999, pp. 167 y 168.

162 Estatuto de la CPI, artículo 68. "Protección de las víctimas y los testigos y su participación en las actuaciones... 3. La Corte permitirá, en las fases del juicio que considere conveniente, que se presenten y tengan en cuenta las opiniones y observaciones de las víctimas si se vieren afectados sus intereses personales y de una manera que no redunde en detrimento de los derechos del acusado o de un juicio justo e imparcial que sea incompatible con éstos" (resaltado nuestro).

163 Estatuto de la CPI, artículo 75. "Reparación a las víctimas. 1. La Corte establecerá principios aplicables a la reparación, incluidas la restitución, la indemnización y la rehabilitación, que ha de otorgarse a las víctimas o a sus causahabientes. Sobre esta base, la Corte, previa solicitud o de oficio en circunstancias excepcionales, podrá determinar en su decisión el alcance y la magnitud de los daños, pérdidas o perjuicios causados a las víctimas o a sus causahabientes, indicando los principios en que se funda. 2. La Corte podrá dictar directamente una decisión contra el condenado en la que indique la reparación adecuada que ha de otorgarse a las víctimas, incluidas la restitución, la indemnización y la rehabilitación. Cuando proceda, la Corte podrá ordenar que la indemnización otorgada a título de reparación se pague por conducto del Fondo Fiduciario previsto en el artículo 79. 3. La Corte, antes de tomar una decisión con arreglo a este artículo, tendrá en cuenta las observaciones formuladas por el condenado, las víctimas, otras personas o Estados que tengan un interés, o las que se formulen en su nombre". 
miento y Prueba de la CPI define lo que debe entenderse por víctimas. ${ }^{164}$ No obstante, tales referencias, a pesar de ser innovadoras en el ámbito de la jurisdicción penal internacional, son limitadas si las comparamos con el desarrollo en los sistemas de protección de derechos humanos, y en especial, del sistema interamericano, de ahí que la CPI se ha concentrado precisamente en la configuración jurídica de las víctimas, para, entre otros derechos, garantizarles el derecho a una reparación efectiva. La CPI, con base en la regla 85.a, ha señalado la presencia concurrente de cuatro requisitos para la configuración de las víctimas. ${ }^{165}$

En este contexto, la Pre-Trial Chamber I de la CPI, en relación a los hechos acaecidos en el Congo, ${ }^{166}$ determinó que una vez abierta la investigación existe el derecho de la víctima a participar, con miras a la lucha contra la impunidad. De esa forma, ha señalado que la víctima puede participar en la fase de investigación, ${ }^{167}$ a partir del criterio de intereses personales (personal interests), lo cual constituye una atribución procesal. En tal sentido, la Pre-Trial Chamber I de la CPI señaló lo siguiente:

In the light of the core content of the right to be heard set out in article 68(3) of the Statute, persons accorded the status of victims will be authorized, notwithstanding any specific proceedings being conducted in the framework of such an investigation, to be heard by the Chamber in order to

164 Reglas de Procedimiento y Prueba de la CPI, artículo 85. "Definición de víctimas. Para los fines del Estatuto y de las Reglas de Procedimiento y Pruebas: a) Por 'víctimas' se entenderá las personas naturales que hayan sufrido un daño como consecuencia de la comisión de algún crimen de la competencia de la Corte b) Por víctimas se podrá entender también las organizaciones o instituciones que hayan sufrido daños directos a alguno de sus bienes que esté dedicado a la religión, la instrucción, las artes, las ciencias o la beneficencia y a sus monumentos históricos, hospitales y otros lugares y objetos que tengan fines humanitarios".

165 CPI, Situation in the Republic Democratic of the Congo Decision on the Applications for Participation in the Proceedings of VPRS1, VPRS2, VPRS3, VPRS4, VPRS5 and VPRS6. Decisión del 17 de enero de 2006, parágrafo 79.

166 Idem.

167 La CPI señaló: "With regard to article 68(3) [el artículo 68 del Estatuto de la CPI se refiere a la protección de las víctimas y los testigos y su participación en las actuaciones], the Chamber considers that it imposes an obligation on the Court vis-à-vis victims. The use of the present tense in the French version of the text ("la Cour permet") makes it clear that the victims' guaranteed right concretely and effectively". Ibidem, parágrafo 71 . De esa forma, la CPI determinó que una vez abierta la investigación las víctimas tienen derecho a participar, con miras a la lucha contra la impunidad. 
present their views and concerns and to file documents pertaining to the current situation in the DRC [República Democrática del Congo]... the Chamber has a dual obligation: on the one hand, to allow victims to present their views and concerns, and, on the other, to examine them. ${ }^{168}$

En esta decisión se establecen como requisitos específicos para poder participar que: a) El solicitante sea un individuo o persona legal; b) Existencia de un crimen ratione materiae de la CPI en la situación bajo investigación; c) El solicitante haya sufrido algún tipo de daño previsto en la Regla 85 (definición de víctimas) ${ }^{169}$ de las Reglas de Procedimiento y Prueba, y d) La existencia de un vínculo de causalidad entre el crimen y el daño alegado. ${ }^{170}$

El primero consiste en establecer si los reclamantes eran personas naturales. Al respecto se debe recordar que si bien, de acuerdo a las circunstancias del caso en concreto, sólo se encontró esta categoría de víctimas, es posible que determinada clase de organizaciones también califiquen dentro de esa categoría. La CPI empleó una definición negativa de persona natural al considerar que ésta es aquella persona que no es una de naturaleza jurídica. ${ }^{171}$ Ahora bien, es interesante citar el razonamiento que hace la CPI sobre el término "miembro familiar" en el Estado del Congo en el cual acaecieron los hechos. Al respecto, frente a cierta vaguedad para el establecimiento de vínculos familiares — según patrones occidentales de filiación - la CPI afirmó apropiadamente que en el contexto africano, una persona puede llamar "padre", "madre", "hermano" o

\section{Idem.}

169 Reglas de Procedimiento y Prueba. Adoptada por la Asamblea de Estados Partes. Primera Sesión, Nueva York, ICC-ASP/1/3, 3-10 de octubre de 2002. Artículo 85. "Definición de víctimas. Para los fines del Estatuto y de las Reglas de Procedimiento y Pruebas: a) Por 'víctimas' se entenderá las personas naturales que hayan sufrido un daño como consecuencia de la comisión de algún crimen de la competencia de la Corte; b) Por víctimas se podrán entender también las organizaciones o instituciones que hayan sufrido daños directos a alguno de sus bienes que esté dedicado a la religión, la instrucción, las artes, las ciencias o la beneficencia y a sus monumentos históricos, hospitales y otros lugares y objetos que tengan fines humanitarios".

170 CPI, Situation in the Republic Democratic of the Congo Decision on the Applications for Participation in the Proceedings of VPRS1, VPRS2, VPRS3, VPRS4, VPRS5 and VPRS6. Decisión del 17 de enero de 2006, parágrafos 79-101.

171 Ibidem, parágrafo 80. 
"hermana", sin poseer en realidad alguna clase de vínculo de filiación biológico con la persona respectiva.

De esa forma tales términos implican una interpretación flexible según el particular contexto socio-cultural en el cual son empleados. ${ }^{172} \mathrm{Tal}$ razonamiento será de especial valía en las futuras decisiones de las cámaras de la CPI, con el fin de establecer el espectro de víctimas y beneficiarios de las reparaciones por los daños sufridos. Adicionalmente, debemos señalar que la Pre Trial Chamber I ${ }^{173}$ en su última decisión sobre el tema, basándose en jurisprudencia de la Corte IDH,${ }^{174}$ ha señalado que además de las víctimas (en sentido estricto), también son cubiertas por la Regla 85 tanto los familiares como los dependientes de las víctimas, siempre que se prueben los requisitos que se desarrollan en los siguientes parágrafos.

El segundo requisito consiste en demostrar que las personas naturales hayan sufrido un daño. Pese a que ni en el Estatuto de la CPI ni tampoco en el texto de las Reglas de Procedimiento y Prueba se define el término daño; la CPI se ha pronunciado de conformidad con los derechos humanos internacionalmente reconocidos. ${ }^{175} \mathrm{La} \mathrm{CPI}$, sin perjuicio de lo que pueda establecer durante el desarrollo del proceso, estableció que era suficiente la existencia de un daño sufrido para atribuir el estatus de víctima, durante la fase de investigación. ${ }^{176}$

El tercer requisito acumulativo fue verificar si los crímenes caían dentro de la jurisdicción de la CPI, de acuerdo a las competencias ratione materiae, personae, loci y temporis. ${ }^{177}$ Finalmente, el cuarto requisito consiste en la existencia entre un vínculo causal entre los crímenes bajo

172 Ibidem, parágrafo 139.

173 CPI, Pre Trial Chamber I. Decision on the Applications for Participation in the Proceedings Submitted by VPRS 1 to VPRS 6 in the Case the Prosecutor $v$. Thomas Lubanga Dyilo. Decisión del 29 de junio de 2006, p. 7.

174 Se citaron los casos Velásquez Rodríguez v. Honduras, Fairén Garbi y Solís Corrales $v$. Honduras, "Niños de la calle" v. Guatemala, "Panel blanca" v. Guatemala.

175 Estatuto de la CPI, artículo 21. "Derecho aplicable... 3. La aplicación e interpretación del derecho de conformidad con el presente artículo deberá ser compatible con los derechos humanos internacionalmente reconocidos, sin distinción alguna basada en motivos [sigue una enumeración no taxativa de motivos de discriminación]".

176 CPI, Situation in the Republic Democratic of the Congo Decision on the Applications for Participation in the Proceedings of VPRS1, VPRS2, VPRS3, VPRS4, VPRS5 and VPRS6. Decisión del 17 de enero de 2006, parágrafos 81 y 82.

177 Ibidem, parágrafos 83-93. 
la jurisdicción de la CPI y el daño sufrido, es decir que los daños se hayan originado como resultado de los crímenes. La CPI estableció también que, en la fase de investigación, no era necesario determinar la naturaleza del vínculo causal ni tampoco la identidad de las personas responsables de tales hechos ilícitos. ${ }^{178}$ Ahora bien, en su pronunciamiento más reciente sobre el tema la Pre Trial Chamber I, ${ }^{179}$ no atribuyó a todos los solicitantes la condición de víctimas toda vez que no pudieron demostrar precisamente el vínculo causal ya referido.

La posición de víctima, una vez que se ha verificado, implica las siguientes facultades: a) Presentación de observaciones generales en relación con la investigación ante la Sala; b) Envío de materiales relativos a delitos cometidos en la situación bajo investigación; c) Acceso a la parte pública del sumario, y d) Notificación de situaciones y decisiones de carácter público.

A su vez se hizo referencia a la determinación caso a caso en relación con: a) Participación en actividades procesales específicas; b) Acceso a materiales confidenciales del sumario relativos a actividades procesales específicas en las que se las autorice participar y c) Notificación de actuaciones y decisiones.

\section{A MANERA DE CONCLUSIÓN}

Como ha podido verificarse, la subjetividad jurídica internacional del individuo ha pasado de una negación en el derecho internacional clásico hacia un reconocimiento en el derecho internacional contemporáneo. Ahora bien, el desarrollo de la dimensión activa de esta subjetividad presenta diferentes niveles de desarrollo según el sistema en el que nos encontremos.

En efecto, mientras que en el contexto del sistema europeo de protección de derechos humanos encontramos que se da de manera plena (ius standi), en el caso del sistema interamericano tal subjetividad es limitada (pleno locus standi in judicio). No obstante, la participación del individuo, en este segundo sistema regional, es más elevada que el esquema

178 Ibidem, parágrafo 94.

179 CPI, Pre Trial Chamber I. Decision on the Applications for Participation in the Proceedings Submitted by VPRS 1 to VPRS 6 in the Case the Prosecutor $v$. Thomas Lubanga Dyilo. Decisión del 29 de junio de 2006, p. 8 . 
quasi-jurisdiccional del sistema universal de protección de derechos humanos. Por su parte, el esquema introducido por la CPI es innovador toda vez que permite la participación de las víctimas en un proceso penal internacional, algo inédito antes de ese hito.

En todo caso, en términos generales, existe la tendencia a fortalecer la dimensión activa de la subjetividad jurídica internacional en el ámbito del derecho internacional de los derechos humanos (casos de los sistemas interamericano y africano), así como también la introducción de tal dimensión en otras áreas del derecho internacional (caso de la CPI). 